\title{
40. STRUCTURAL FEATURES OF THE MIDDLE AMERICA TRENCH SLOPE OFF SOUTHERN MEXICO, DEEP SEA DRILLING PROJECT LEG $66^{1}$
}

\author{
Neil Lundberg and J. Casey Moore, Earth Sciences Board, University of California, Santa Cruz, California
}

\begin{abstract}
The distribution of bedding tilts, penetrative fabrics, and discrete structures in Leg 66 cores correlates distinct tectonic environments and basement types landward of the Middle America Trench. The lower slope, underlain by a zone of landward-dipping reflectors, is characterized by zones of inconsistent bedding dip, stratal disruption, and scaly mudstone, with deformation most active close to the trench. The upper slope, principally underlain by continental crust, exhibits none of these features and is characterized by mesoscopic folding, with local development of spaced foliation and veins. A transition zone between the continental crust and the zone of landward dipping reflectors includes structural features common to both but is distinguished by predominantly oblique-slip faults, whereas all other sites exhibit mainly dip-slip faults.

Stratal disruption and scaly mudstone, characteristics of many alleged uplifted subduction complexes, are concentrated within the lower slope environment in sediment interpreted as trench and lowermost trench slope deposits. Bedding has been disrupted very early in some intervals of partially consolidated mud and unconsolidated sand, and sand has remained unconsolidated even where intercalated in stratally disrupted intervals with mud that has dewatered and lithified sufficiently to form scaly mudstone.
\end{abstract}

\section{INTRODUCTION}

Subduction zones constitute one of the most cormplex of structural environments. Intricate folding, thrust faulting, and stratal disruption characterize deformation in presumed ancient subduction zone complexes. The structural features of subduction zones are readily observable in ancient rocks, though the processes and physical conditions associated with their formation must be inferred. Conversely, drill cores from modern subduction zones are limited in quantity and sample no deeper than 1200 meters beneath the trench slope, yet they do provide close constraints on the processes and conditions associated with the development of any included structures.

Exactly how structural features of subduction complexes form incites considerable controversy. Principal points of dispute include whether the operative processes are driven by gravitational or tectonic forces (Elliott, 1976; Seely, 1977), whether the deformation occurs when the sediments are lithified or unlithified (Hsü, 1974; Cowan, 1978), whether the complex mixtures observed are due to surficial gravity gliding or to tectonic mixing (Maxwell, 1974; Hsü, 1974), and whether the structures are due to flattening or simple shear (Draper, 1978; Quinquis et al., 1978). Studies on different examples of both modern active margins and presumed ancient subduction complexes have demonstrated wide variability in the dominant processes. In addition, multiple studies of specific localities have often produced differing interpretations. Even those points generally agreed upon by most workers often lack direct geological evidence from modern active margins. The popular

\footnotetext{
1 Initial Reports of the Deep Sea Drilling Project, Volume 66.
}

imbricate thrust model proposed on the basis of geophysical studies on accretionary margins has been shown to be consistent with the geology of a number of uplifted presumed subduction complexes, but direct sampling of modern subduction zones has thus far offered few constraints on the processes through which subduction complexes evolve. Aspects remaining to be evaluated include the importance of imbricate thrusting throughout the trench slope; the incorporation of slope sediments into the subduction complex, and differences in the deformational history of trench versus trench slope sediments. In light of the variability of the tectonic style of convergent margins (Silver and Beutner, 1980; Scholl et al., in press), careful studies utilizing the unequivocal setting of modern environments are critical. This chapter represents one such attempt.

Drilling on DSDP Leg 66 provided the greatest number of sites spanning the trench and forearc region of any active margin transect to date (Fig. 1). In the present study we present a preliminary structural study of cores based on both macroscopic and microscopic levels of observation. A graphic structural log represents the location, frequency, and orientation of macroscopic structural features, which are also illustrated by photographs. The penetrative structural fabrics are described microscopically and illustrated by photomicrographs.

\section{TECTONIC SETTING}

The Leg 66 transect off southern Mexico crosses a narrow shelf and steep inner trench slope lacking a welldefined forearc basin (Fig. 1; Mejorada, 1976). The adjacent Middle America Trench is characterized on the basis of seismic data by a series of discontinuous sediment ponds with a maximum of 625 meters of turbidite fill overlying about 200 meters of hemipelagic to pelagic sediment that lies on Miocene ocean crust. 


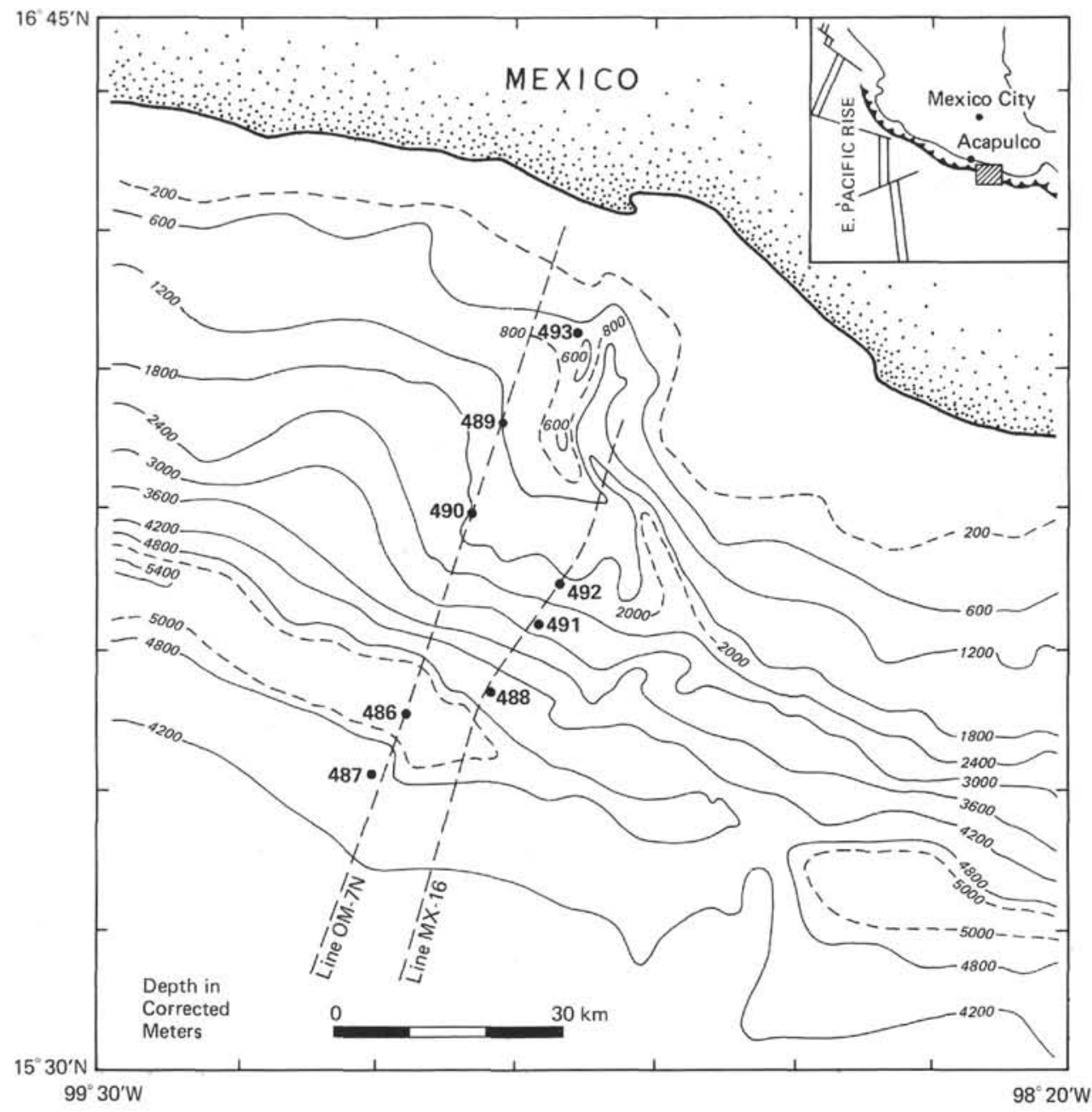

Figure 1. Location of Leg 66 drilling sites. (Dashed lines indicate extent of seismic lines OM-7N and MX-16.)

In the Leg 66 area the Cocos Plate converges with the North American Plate at a rate of $7 \mathrm{~cm} / \mathrm{y}$. along an azimuth of about $38^{\circ}$ (Minster and Jordan, 1978). Generalized plate tectonic reconstructions and the magmatic history of the continental margin both suggest that the Mexican portion of the North American Plate and the Cocos and other Pacific Ocean plates have been converging at least intermittently for $100 \mathrm{~m} . \mathrm{y}$. (Karig et al., 1978). An extensive zone of offscraped deep sea sediments and a broad forearc region would be expected along this margin in view of the long history of convergence. However, the geology of coastal exposures as well as Leg 66 drilling results indicate that continental basement rocks extend to within $35 \mathrm{~km}$ of the trench. Except for basement terrane, we know of no rocks older than Neogene in the offshore region of southern Mexico, which suggests removal of a pre-existing forearc and accretionary zone. The present phase of accretion apparently commenced in the Neogene, probably at the same time as inception of magmatism in the Trans-Mexican Volcanic Belt (Cantagrel and Robin, 1979).

Along the Leg 66 transect the drilling and geophysical data define two tectonic environments within the inner trench slope which are underlain by landward-dipping reflectors and continental crust, respectively, and separated by a narrow transition zone (Fig. 2). For purposes of discussion we refer to the area underlain by landward-dipping reflectors as the "lower slope" and use "upper slope" to designate the area over the transition zone and continental crust. The landward increase in age of the zone of landward-dipping reflectors and their interpretation as bedding surfaces suggest that landward-dipping thrust faults have produced a stratigraphic inversion across the lower slope (Moore et al., 1979). In all holes that penetrated the zone of dipping reflectors (at Sites 488, 491, and 492), we initially encountered muddy slope sediments that passed at greater depth into interbedded sands and muds which are interpreted as uplifted trench deposits. The hemipelagic slope muds vary little in lithology and are composed mainly of terrigenous silt, clay, and minor fine sand; carbonate and biogenic silica are rarely important constituents. The sediments interpreted as trench deposits are thickly bedded sands and mudstones which lithologically and acoustically resemble the modern trench sediments (see site chapters for details). In the holes over 


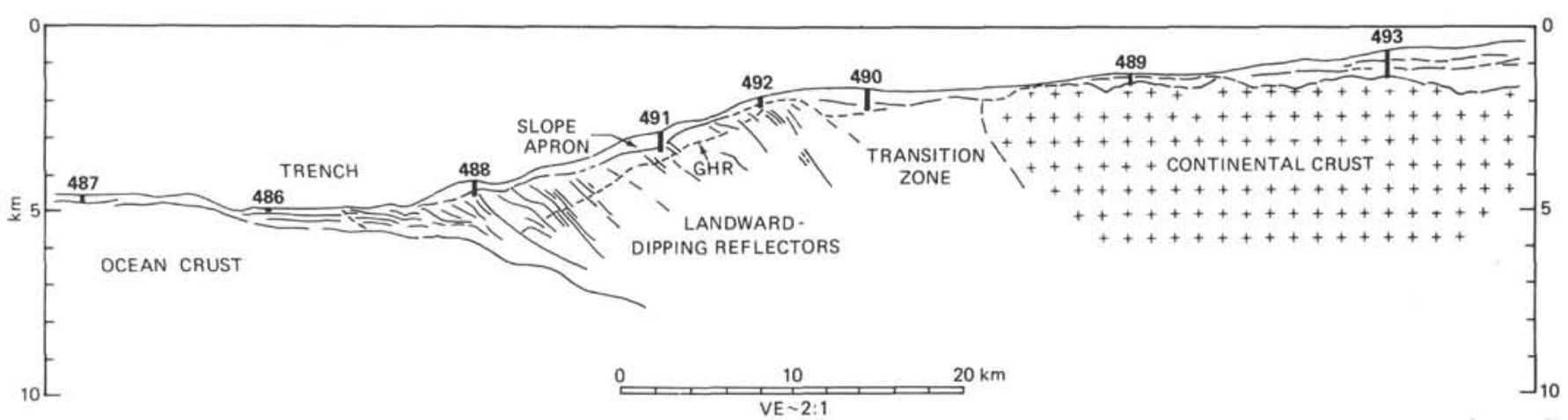

Figure 2. Schematic cross section of the Leg 66 area derived from a composite depth section of seismic lines OM-7N and MX-16.

continental crust (at Sites 489 and 493) we penetrated a predominantly muddy sequence that coarsens downsection into a basal transgressive sand sequence directly overlying basement. Thus our structural study describes deformational features developed in sediment deposited on a pre-existing continental basement as well as those developed in uplifted deep sea deposits.

\section{MACROSCOPIC STRUCTURAL FEATURES}

\section{METHODS AND INTRODUCTORY REMARKS}

We collected data on the occurrence and orientation of bedding, pervasive secondary fabrics, fractures and faults, folds, and veins, where present in all the Leg 66 cores. At the La Jolla Repository Lundberg rechecked all structural data acquired at sea and collected substantial new information. We measured true dips and dip azimuths in each case and noted coherent intervals in the cores throughout which no demonstrable drill-induced rotation has taken place. These coherent intervals permit the assessment of comparative orientations of bedding and secondary features. The vertical deviations of the drill holes as determined by a downhole instrument were generally not over $1^{\circ}$ and never exceeded $3^{\circ}$. Since these deviations are comparable to our measurement errors we have assumed drill holes to be vertical in all cases.

The graphic structural log (Fig. 3, back pocket) depicts the location and dip, where applicable, of structural features of the Leg 66 cores. The sites are arranged in geographical order across the transect drilled, from the lowermost trench slope (Site 488) to the uppermost trench slope (Site 493). Sediments recovered at the remaining two sites, in the trench (Site 486) and on the outer trench slope (Site 487), do not exhibit bedding surfaces or structural features, probably because of the unlithified nature of the sediment and drilling deformation in the short intervals drilled.

For purposes of graphic portrayal and discussion, we have divided structural data into three groups: bedding tilts; penetrative secondary fabrics (pervasive on a scale of millimeteres to a few centimeters); and discrete structures, including fractures and faults, folds, and veins. We discuss each group of data in turn, progressing from the seawardmost to the landwardmost sites. We discuss drill-induced structures where appropriate in the text; see Leggett (this volume) and Arthur et al. (1980) for more detailed discussions of drilling artifacts.

The lack of measured dips of bedding in a given interval is in some cases due to a lack of resolvable bedding (as in all sediment recovered at Sites 486 and 487) and in other cases to extreme drilling deformation. Identifica- tion of folds and some faults depends similarly on the resolution of bedding. The development of penetrative fabrics and discrete fractures is clearly related to the degree of lithification, which varies significantly with depth. In addition, core recovery governs the density of observable structural features by limiting represented intervals.

\section{Orientation of Bedding}

We classify bedding dips as low $\left(0^{\circ}-20^{\circ}\right)$, moderate $\left(20^{\circ}-40^{\circ}\right)$, or steep $\left(40^{\circ}-90^{\circ}\right)$ and group them graphically on this basis in Figure 4 , together with age and lithology of the sediment. The uppermost bedding dips in all cores from inner trench slope holes are low or horizontal, suggesting that the lack of resolvable bedding orientations in the soupy upper sediment of most of the holes is not a critical problem. Deeper intervals from several holes also lack resolvable bedding, but nowhere do these gaps exceed 80 meters in thickness. In cores displaying numerous bedding surfaces, we measured representative bedding tilts and noted consistency of tilts $\left( \pm 5^{\circ}\right.$ over a 1.5 -meter section) where present.

Patterns in bedding tilts reveal similarities in the three lower slope sites, Sites 488, 491, and 492. Intriguing zones of inconsistent bedding dip occur only in cores from these sites. In each case the zones of inconsistent dip, or chaotic zones, separate intervals of consistently low or moderate dips. Cores recovered at Site 491 show two well-documented chaotic zones separating three clearly defined zones of consistently low bedding dip. Two of these chaotic zones (Site 488 at 200-225 m, and Site 491 at $180-215 \mathrm{~m}$ ) coincide with intervals that include stratal disruption. The chaotic zone in Site 488 cores coincides with an interval of anomalously low porosity and high density as well (see Shephard, this volume). These zones of inconsistent dip are probably related to major structures within the inner trench slope, most likely fault zones. Such fault zones may represent the basal surfaces of large-scale slumps on the lower slope and thus be governed largely by the slope angle (and possibly by high pore fluid pressure as well). Alternatively, these chaotic zones may represent deformation resulting from deep-seated faults related to tectonic processes.

The zones of inconsistent bedding dips in the lower slope should appear as chaotic zones on high-resolution 


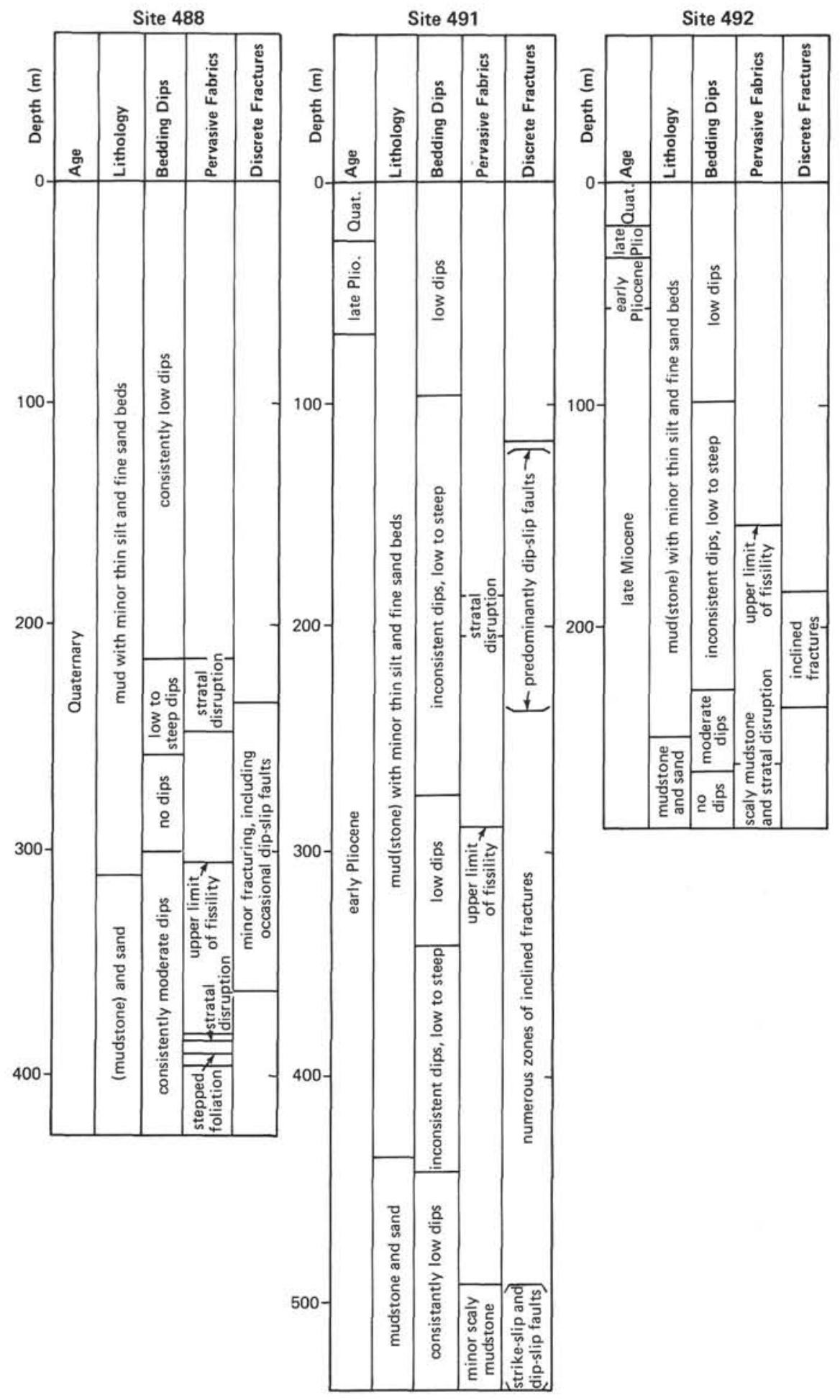

Figure 4. Generalized structural log for inner trench slope sites based on data in Figure 3, with sediment age and lithology. 


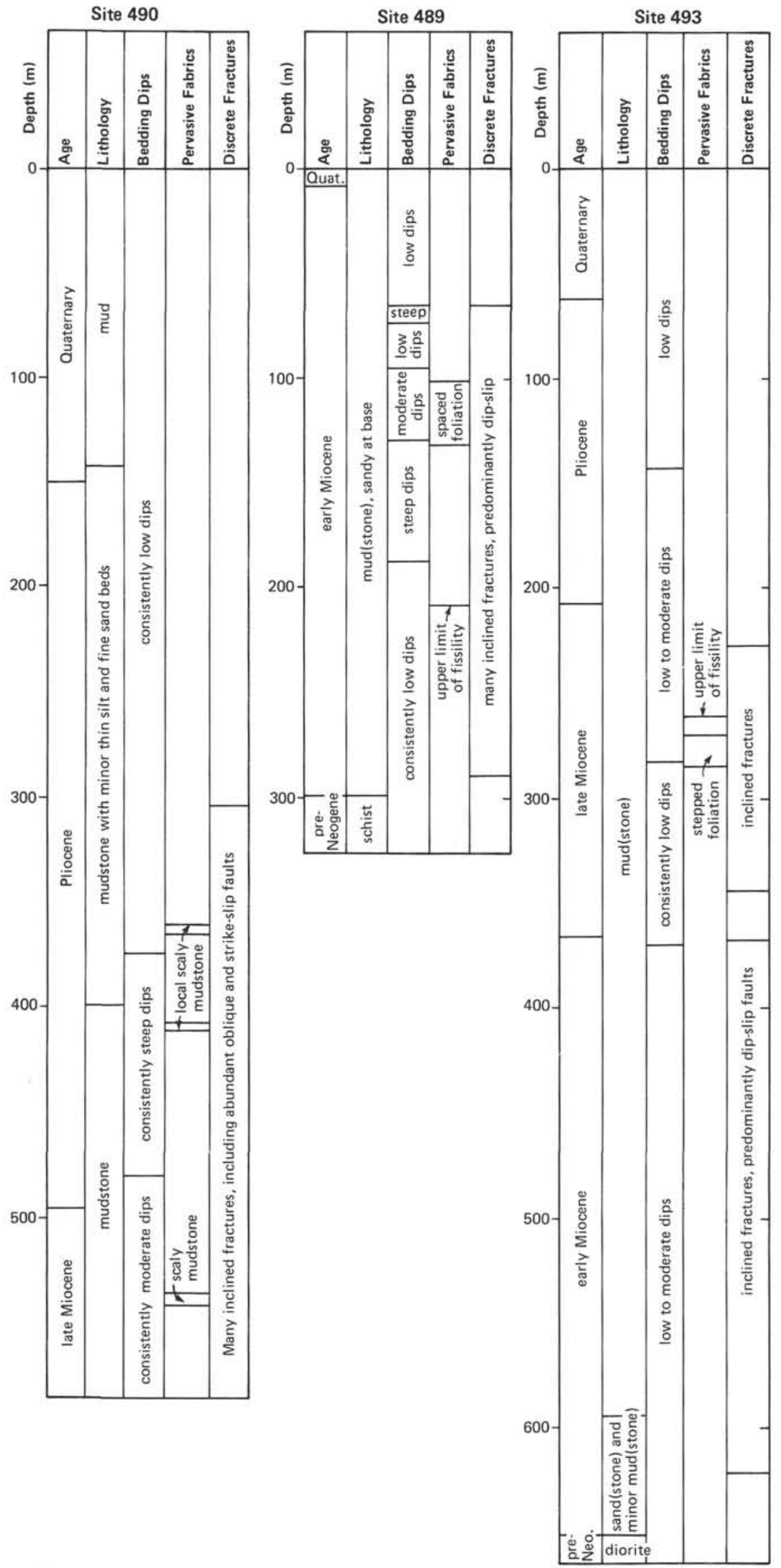

Figure 4. (Continued). 
seismic reflection profiles, whereas there should be coherent reflectors resolvable in the zones of consistently low and possibly moderate dip. Thus a detailed high-resolution seismic reflection survey might provide the geometric constraints necessary to distinguish between slump deposits and deeply rooted thrust faults in order to determine the origin of the chaotic zones.

The basal sediments recovered at Sites 488 and 491, inferred to be uplifted trench deposits, show consistently low or moderate bedding dips and, surprisingly, lack the patterns of inconsistent attitudes. Yet basal sediments from Site 492 , also inferred to be uplifted trench deposits, include stratally disrupted sand and scaly mudstone that do not exhibit resolvable bedding dips.

The bedding dips we measured from uplifted trench sediments in the lowermost trench slope (Site 488) are as steep as or steeper than those measured in uplifted trench sediments farther up the slope (Sites 491 and 492). Apparently, trench sediments incorporated into the accretionary zone are tilted rapidly during initial uplift and emplacement rather than progressively tilted throughout uplift (see also Shipley, this volume).

Bedding dips measured in the sediments of the transition zone (Site 490) and in sediments overlying the continental crust (Sites 489 and 493) are locally consistent and tend to vary smoothly downhole. Probably the simplest explanation of this pattern of dips is folding, on a scale too large to see in the cores but too small to resolve seismically. There is an interval in Hole 493, between 280 and 372 meters, that consists of beds with consistently horizontal to very low dips and is bounded above and below by sharp transitions to beds with low to moderate dips. The basal boundary of this nearly flat-lying interval occurs near a significant hiatus that apparently represents an angular unconformity of at least $11^{\circ}$. The upper boundary of the flat-lying interval at Site 493 coincides with a radiolarian zone boundary and may represent a decollement surface along which the overlying sediment (over 100 meters of gently to moderately dipping beds) has slumped. The seismic reflection profile nearest Site 493 (Line MX-13; see Shipley, this volume) shows strong reflectors that dip up to $8^{\circ}$ in the interval corresponding to the nearly horizontal beds recovered at 280 to 372 meters and less welldefined reflectors both above and below it.

\section{Fissility}

Fine-grained sediments in the deeper sections of the inner trench slope sites (Site 488-493) show intermittent fissility, defined by shaly partings parallel to bedding (Plate 1, Fig. 1). Fissility occurs only at sub-bottom depths greater than 150 meters; where present at depths shallower than 250 meters (Sites 489 and 492), the fissile sediments are older (Miocene) than sediment at equivalent depths at the other sites and underlie hiatuses, suggesting deeper burial at some point in their diagenetic history. We interpret the fissility as a feature of gravitational compaction. Interestingly, although fine-grained sediments at Site 490 do not exhibit fissility, they do include Miocene mudstones recovered at deeper than 500 meters. This finding may be related to the unusually high degree of bioturbation at that site which probably destroyed a depositional alignment of platy sediment grains, an explanation supported by an inverse correlation between bioturbation and fissility at Site 493 .

\section{Stepped Foliation}

We use the term "foliation" in the general sense to describe any planar fabric in sediment or rock in Leg 66 cores in order to differentiate secondary fabrics from features for which the more restricted term "cleavage" is generally accepted.

A secondary foliation composed of a parallel set of discontinuous parting surfaces, each less than $1 \mathrm{~cm}$ in length and at a distinct angle to bedding, occurs locally in Hole 488 at 391.5 meters and in Hole 493 at 275 and 287 meters. In each case the foliation crosscuts tilted bedding at a steeper angle and so probably cannot be attributed to simple gravitational compaction. The foliation discontinuously "steps" across bedding surfaces (Plate 1, Fig. 2), hence the informal designation of "stepped foliation." For example, mudstone at $\mathbf{3 9 1 . 5}$ meters in Hole 488 exhibits a parting surface that dips $61^{\circ}$ in approximately the same direction as bedding and a bedding-parallel fissility, both inclined at $45^{\circ}$. The stepped foliation is identical, both macroscopically and microscopically (see the following microscopic description), to a series of discontinuous fractures ("fracture cleavage'") crosscutting bedding in folded trench deposits drilled at Site 298 on the inner slope of the Nankai Trough (Moore and Karig, 1976).

\section{Spaced Foliation}

A spaced foliation is developed in a restricted shallow interval (100-130 m) recovered at Site 489. Parallel dark zones of fine-grained material form parting surfaces that define a penetrative foliation, pervasive on a scale of centimeters (Plate 1, Fig. 3). These surfaces are spaced 0.5 to $2 \mathrm{~cm}$ apart and range from very planar and continuous to slightly sigmoidal and en echelon. Radiographs of slabs show reduced penetration by X-rays through the selvages, or dark zones, that define the spaced foliation, suggesting that these zones are of higher density than the surrounding sediment. The spaced foliation dips $40^{\circ}$ to $65^{\circ}$ in a direction nearly $180^{\circ}$ from that of the bedding dip, which ranges from $25^{\circ}$ to $47^{\circ}$. Some surfaces were open when the cores were split, but the majority were not. The core is easily broken along the healed surfaces; both open and healed surfaces display well-developed striations, probably slickenlines, that plunge subparallel to the dip direction of the foliation. Infrequent small offsets in bedding features and burrows indicate normal dip-slip motion. The restricted interval over which spaced foliation is found as well as the striated slickensides and localized dip-slip displacement suggest it is related to faulting, perhaps to a major normal fault (system) in the upper trench slope. That the shallow depth at which this foliation occurs may be due to erosion of a significant thickness of previously overlying sediment is suggested by a major unconformity (Quaternary mud overlying 
lower Miocene mudstone) above the foliated interval at Site 489.

\section{Stratal Disruption}

Pervasive bedding discontinuities not attributed to primary deposition or to drilling deformation occur in cores from Sites 488,491 , and 492 . Bedding in these zones of stratal disruption is not resolvable macroscopically, despite a marked contrast in sediment types. Zones of stratal disruption commonly show a foliation defined by weakly to strongly oriented elongate lenses of silt to fine sand (Plate 2, Fig. 1). Locally this foliation is also defined by thin, dark zones of fine-grained material, which commonly bound and/or truncate elongate silt and sand bodies. In some cores, a second foliation is suggested by another, fainter set of thin, dark zones of fine-grained material (Plate 2, Fig. 2). Superposition of two $s$ surfaces results in anastomosing thin, dark zones that cut silt and sand bodies. Zones of stratal disruption found at Sites 488 and 491 occur in intervals of very inconsistent bedding dips in which bedding surfaces range from nearly horizontal to nearly vertical (Fig. 3). At Site 488, this interval shows anomalously low porosity and high density (Shephard, this volume).

\section{Scaly Mudstone}

Well-indurated fine-grained sediments in the lower portions of holes drilled at Site 490, 491, and 492 exhibit a fabric of anastomosing polished and slickensided fracture surfaces, pervasive on a scale of millimeters, essentially constituting a scaly mudstone (Plate 2, Fig. 3). Stratal disruption is apparent in examples of scaly mudstone that display clear differences in lithology (Site 492). Sand intervals in these examples lack cement and have remained unconsolidated, whereas the fine-grained portions are well indurated (Plate 3, Fig. 1). Intervals of scaly mudstone that have not been disrupted by drilling exhibit at least one foliation.

Anastomosing polished and striated fracture surfaces characterize a penetrative fabric developed throughout most of the fine-grained sediment in the basal 35 meters at Site 492 . Even at 267 meters in Hole 492 , drilling has not disrupted the scaly mudstone, and two foliations defined by this fabric are inclined at about $75^{\circ}\left(\mathrm{S}_{1}\right)$ and $45^{\circ}\left(\mathrm{S}_{2}\right)$ along approximately the same dip azimuth (Plate 2, Fig. 2). The earlier, steeper foliation $\left(\mathrm{S}_{1}\right)$ in this sample is defined by more densely spaced and less planar thin, dark zones of fine-grained material than is the more shallowly inclined $\mathrm{S}_{2}$ surface. Bedding is not resolvable macroscopically.

Intermixing of sand and scaly mudstone is particularly well illustrated in an impregnated, slabbed, and polished interval of upper Miocene sediments taken from the base of the section recovered at Site 492 (Plate 3, Fig. 2). A semipenetrative planar fabric is present, defined by anastomosing healed fracture surfaces (even after impregnation, polished chips of mudstone broke off this sample during cutting and polishing). Primary features have largely been destroyed, although relict bedding is suggested locally and appears to be folded in places.

\section{Discussion of Pervasive Fabrics}

Zones of stratal disruption and scaly mudstone are restricted to sites overlying or just landward of the zone of tilted reflectors (Fig. 3). Unfortunately it is not possible to distinguish between gravitational and tectonic origins for these fabrics. However, the occurrence of stratal disruption and scaly mudstone in Leg 66 samples confirms that these features develop in an accretionary zone at shallow levels (several hundred meters) where sandy intervals are still unconsolidated, as had been discovered during Japan Trench drilling (Arthur et al., 1980).

Spaced foliation is restricted to a short interval fairly shallow in the section recovered at Site 489. This foliation is interpreted to be fault-related because it is not found deeper in the sediments at this site, although drilling penetrated to continental basement.

Stepped foliation is present in cores from both the lowermost and uppermost inner trench slope sites and so does not appear to be a diagnostic feature for distinguishing tectonic environments within the trench slope. Because the foliation dips more steeply than bedding in each case, it cannot be explained simply by gravitational compaction. Alternatively, the stepped foliation might be due to localized hydrofracturing. Fissility, on the other hand, developed parallel to bedding in holes drilled at all trench slope sites except Site 490 and is interpreted as a result of gravitational compaction. The upper limit of fissility is at depths of 150 to 250 meters in Leg 66 holes, and it developed preferentially in fine-grained laminated sediment.

\section{Fractures and Faults}

We measured orientations of representative fractures where present in all Leg 66 cores. For each fracture analyzed, we measured the true dip and dip azimuth of the fracture surface, as well as the trend and plunge or rake and rake reference direction of each resolvable set of striations, or slickenlines. Where possible, we determined the sequence of striation development. In order to classify striated faults, we call those with striations that rake $70^{\circ}$ or more dip-slip faults, those with striations that rake less than $20^{\circ}$ strike-slip faults, and the remainder oblique-slip faults. We used offset beds and burrows where present to determine the sense of offset along minor faults and noted the sense of steps developed on slickensides, although these should be interpreted with caution (Durney and Ramsey, 1973; Hobbs et al., 1976). We also noted consistent parallel sets of fractures, as well as coherent intervals over which the dip azimuths of various fractures can be compared. We discuss later the distinction between natural, or preexisting, fractures and artificial fractures induced by drilling and/or handling.

Discrete fractures are present in cores from all inner trench slope sites but are absent in cores from the trench and outer trench slope sites. The short interval cored in the trench at Site 486 consists of soupy to soft sand and mud and is too poorly lithified to be fractured. The physical properties data suggest that the hemipelagic 
mud and pelagic clay recovered at Site 487 on the outer trench slope (Cocos Plate) is also too poorly lithified to be fractured, as the porosity of the deepest sediment of Hole 487 is much higher than that of sediment from any inner trench slope site at the depth of shallowest fractures ( $75 \%$ as contrasted with 38 to $53 \%$; see Shephard, this volume, for details).

Discrete fractures in Leg 66 cores are generally open and range from very planar, smoothly polished surfaces to undulatory, curviplanar, and/or hackly surfaces. They are often striated (Plate 3, Fig. 3), occasionally with multiple sets of striations oriented in discrete directions, and frequently display stepped surfaces. Fractures commonly occur in sets (of three or more fractures) where coherent (nonrotated) core intervals are sufficiently long. Sets of subparallel fractures are generally striated and are spaced about every 10 to $30 \mathrm{~cm}$. Fracture sets that are pervasive on a much smaller scale (millimeters to a few centimeters) are distinguished from discrete fractures on that basis and described in the section on penetrative fabrics. These commonly exhibit healed fractures, in contrast to the generally open nature of the discrete fractures. Brecciated intervals are present in several holes, with evidence of predrilling (partially cemented) fractures in only one, at 260 to 262 meters in Hole 488, on the lowermost trench slope.

On the graphic structural log (Fig. 3) discrete fractures are plotted inclined downward from the left unless there are two or more distinct directions of dip (azimuths more than $90^{\circ}$ apart) for fractures in a coherent interval, in which case the dips of the less prevalent fractures are plotted inclined down from the right.

Most of the fractures in cores from Site $\mathbf{4 8 8}$ are fairly steeply inclined; most occur in the interval between 276 and 311 meters; and most of the striated fractures are dip-slip faults. Fractures are surprisingly scarce here, probably because of poor recovery and the poorly consolidated nature of the lower portion of the section drilled.

Fractures are more evenly distributed throughout the section recovered at Site 491 than that at Site 488 . The shallowest fractures at Site 491 occur at a lesser depth than those at Site 488 (121 m as contrasted with $235 \mathrm{~m})$ but in older sediment ( $3.3 \mathrm{~m}$.y. as compared with 0.6 m.y.). Fault surfaces in cores from Site 491 are generally steep and dip-slip faults predominate, but a number of strike-slip faults occur at the base.

Discrete fractures are scarce in cores from Site 492, in part because fractures are pervasive in the basal 30 meters. The shallowest fracturing is at 183 meters, in upper Miocene sediments ( 8.6 m.y.). Thus within the lower trench slope the age of the youngest fracturing increases away from the trench, consistent with the decreasing rate of deformation with distance from the trench (Moore et al., 1979).

The striking feature in cores from Site 490 is the abundance of oblique-slip faults, which are much more prevalent than dip-slip or strike-slip faults. The youngest fractured sediment at Site 490 is Pliocene mudstone (about $2.7 \mathrm{~m} . \mathrm{y}$.) at 315 meters, deeper than at any other site and younger than at all sites except Site 488 .
Discrete fractures cut much of the section recovered at Site 489. Dip-slip faults predominate, with some oblique-slip and strike-slip faults present. The youngest fractured sediment, lower Miocene (about 17.3 m.y.) mudstone at 69 meters, is older and shallower than at any other site, but this is probably an artifact of erosion at the overlying middle Miocene through lower Quaternary hiatus.

Dip-slip faults dominate fractures in cores from Site 493 also, although oblique-slip and strike-slip faults occur as well. The youngest fractured sediment is upper Miocene mudstone (about 8.0 m.y.) at 275 meters.

\section{Artificial Fractures}

Many fractures may be drilling and/or handling artifacts, and some can be demonstrated as such. We refer the reader to Arthur et al. (1980) for a useful summary of criteria with which to identify drill-induced deformation. In addition to the clearly artificial features noted by these authors in discussing deformation in Japan Trench cores, however, we are also skeptical of conjugate sets of discrete inclined fractures that are symmetric with respect to the vertical core axis. Loading and unloading of sediment as cores are drilled and retrieved should produce a stress environment below the drill bit, with the vertical axis alternately the direction of of maximum and minimum compressive stress. Because as sediment is cored it is first pushed into the core liner and then pulled up by the core barrel and liner, it should again experience vertical maximum and minimum compressional stress axes. Furthermore, an inordinate proportion of these vertically symmetric conjugate fractures are very nearly perpendicular to the planar surface of the split core (i.e., the intersection of two conjugate fractures is the pole to the plane of the sawn surface), suggesting that fracturing occurred during splitting of the cores. As the core, lying horizontally, is split, the maximum compressive stress is applied by the saw as it is pulled vertically through the core, and the V-shaped trough holding the core may then be enough to make the vertical axis (parallel to the split surface) the direction of minimum compressive stress.

Conjugate normal faults symmetric with respect to the core axis at 210 meters in Hole 491 offset drilling laminations and thus clearly postdate the drilling of the core (Plate 4, Fig. 1). We are skeptical of the natural origin of fractures that display no slickenlines, hackly or rough surfaces, or poorly developed slickenlines indicating purely dip-slip motion.

\section{Discussion of Fractures and Faults}

Fractures with evidence of dip-slip offset, especially normal faults, are present throughout holes drilled at the inner slope sites. At least some of these dip-slip faults are artifacts of drilling and handling; many however, show evidence of later oblique-slip or strike-slip movement, and many are not oriented symmetrically with respect to the core axis and are probably predrilling faults. The presence and density of fractures appear to be related more to the state of sediment lithification than to the position within the accretionary zone, sug- 
gesting that fracture-inducing stresses are present throughout the inner trench slope of this active margin. We assume that the scarcity of fractures recorded at Site 488 is due to poor recovery and to the poorly consolidated nature of the sediments, because the bedding tilts and stratal disruption in the section at Site 488 attest to a very active tectonic environment. At Site 491 a number of strike-slip and oblique-slip faults are interspersed with more prevalent dip-slip faults. The strike-slip and oblique-slip faults are localized for the most part at the base of the drilled section within the uplifted trench sediments and suggest a complex strain history for sediments in this tectonic environment.

A majority of the fractures measured at Site 490 , in the transition zone, display evidence of oblique-slip or strike-slip faulting, and the sediment fractured is younger than at all other sites except the lowermost slope site (Site 488). This movement pattern may result from differential stresses and consequent motions between the two very different crustal types comprising the upper and lower trench slope. The transition zone between the continental crust and the zone of dipping reflectors may constitute a region where a substantial portion of the oblique component of convergence is absorbed.

\section{Folds}

Patterns of tilted bedding suggest megascopic folding at all inner trench slope sites (Fig. 3), though some tilting has undoubtedly been produced by flexure during differential uplift and subsidence across the margin. Folding is not as prevalent on seismic profiles as is suggested by measured dips of cored sediment, possibly owing to a combination of poor seismic resolution of moderate and steep dips, seismically small-scale folding, and/or folding related to faulting. Megascopic fold geometries are difficult to evaluate, because dip directions are largely unknown. In general, however, the holes overlying continental crust and the transition zone exhibit more consistent patterns of bedding and thus probably less complex folding than do those overlying the zone of landward-dipping reflectors.

Numerous small-scale recumbent folds were noted in the shipboard core descriptions. A small-scale fold at Interval $492-26-4,73-85 \mathrm{~cm}$ is defined by a downcore reversal in bedding dip. Here, bedding is represented by subtle color differences in mudstone and the fold defined has a nearly horizontal axial surface and an interlimb angle of about $70^{\circ}$ (Plate 4, Fig. 2).

Upon closer examination, however, most of the "folds" initially recorded could be attributed to bioturbation or drilling deformation. For example, apparently folded stringers of sand at Intervals 491-22-4, $122 \mathrm{~cm}$ and $491-42-1,130-150 \mathrm{~cm}$ are probably parts of large curved burrows lined with sand and cut at a fortuitous angle to resemble folds. Vague folds defined by diffuse color variations at Intervals $491-20-2,20-40 \mathrm{~cm}$ and $492-26-6,140 \mathrm{~cm}$ probably represent soft mudstone swirled by drilling rotation and occur between drilling laminations (horizontal zones where the core was spun during drilling), as are more obviously drill-induced "folds." An apparent fold defined by a downcore change of nearly $180^{\circ}$ in the dip direction of very firm bedded mudstone at Interval $492-14-3,30-50 \mathrm{~cm}$ is probably an artifact of rotation by drilling of an inclined section, although there is no obvious surface of rotation.

As a conservative approach after rechecking the preliminary shipboard data on folds and overturned beds, we reinterpreted a number of these features as possibly artificial. All small recumbent folds and overturned beds, including those that are equivocal, occur in the lower trench slope region at Sites 488, 491, and 492 (Fig. 3). It has not been resolved whether these are tectonic or slump features.

\section{Veins}

Veins are present only in sediment near the base of the section recovered at Site 489 , directly over continental basement. These are planar and steeply dipping veins several millimeters wide, filled with a yellow mineral, probably zeolite.

\section{MICROSCOPIC DESCRIPTION OF FABRICS}

Representative samples were collected for microscopic study of the semipenetrative secondary fabrics developed in the Leg 66 cores. These samples were dried and vacuum-impregnated with epoxy before thin sectioning.

\section{Stepped Foliation}

Microscopically the parting surfaces of the stepped foliation at Site 493 (Interval 493-18-2, 146-150 cm) contain large sheaves of gypsum (Plate 5, Fig. 1). These fractures may have been open at depth, prior to drilling. The gypsum, however, probably crystallized during desiccation of the cores after drilling. There is no evidence for offset along these fractures; nor is there sediment staining or mineral realignment associated with this fabric.

\section{Spaced Foliation}

At a depth of 127.5 meters at Site 489 , bedding and a crosscutting spaced foliation are well defined, macroscopically and microscopically. The parallel thin, dark zones, or selvages, which constitute the parting surfaces of the spaced foliation (Plate 2, Fig. 1) are defined microscopically by dark staining composed of concentrations of fine-grained black to brown material (Plate 5, Fig. 2). This material may represent an insoluble residue of pressure solution or a precipitate of pore fluids migrating through the fractures. The darkened selvages include reoriented platy minerals. X-ray fabric studies also suggest the presence of a preferred orientation in the vicinity of the foliation traces and indicate that the fabric is heterogeneous between these zones (Wayne Zeck, personal communication). Although minute displacements were noted locally on the split cores, we have found no clear evidence of microscopic offsets.

Three stages of spaced foliation development occur in the thin sections. The first (prior to actual fracturing) is defined by a faint trace of dark-stained material, par- 
allel to the well-developed fracture surfaces (Plate 5, Fig. 2). Fine-grained platy minerals within the incipient foliation trace are realigned parallel to the foliation, possibly by mechanical bending of the mineral grains. However, no kinking of individual grains is resolvable microscopically (Plate 6, Fig. 1). The second stage of foliation formation involves a physical break along the foliation trace (Plate 5, Fig. 2). This fracturing is discontinuous and locally exhibits an en echelon pattern. Fracture traces are sinuous, detouring around unbroken detrital grains of silt and even of sand size (Plate 6, Fig. 2). In this second stage the zone of stained sediment matrix and realigned phyllosilicates is generally broader (up to $0.5 \mathrm{~mm}$ ) and more darkly stained than in incipient foliation traces. The third stage of foliation formation is characterized by smooth and straight fracture surfaces bordered by broad and well-defined stained zones in which mineral grains are reoriented parallel to the foliation.

\section{Stratal Disruption}

An example of stratally disrupted mud, silt, and sand from the zone of chaotic dips at Site 488 (238.5 m) exhibits a macroscopic foliation defined by a crude alignment of elongate sand and silt bodies in a mud matrix (Plate 2, Fig. 1). This foliation dips about $25^{\circ}$ and is further defined by anastomosing thin zones of dark fine-grained material that commonly bound sand and silt bodies.

Microscopically the dark zones are composed of subparallel curviplanar concentrations of clay, separating clusters of sand and silt that are relatively free of clay-sized material (Plate 7, Fig. 1). These more coherent clusters of sand and silt appear to be caught in the process of disaggregating by the spalling off of individual grains into bounding clay-rich zones (Plate 7, Fig. 2). Borders of these clusters grade from grain-supported, clay-poor, moderately well-sorted sand and silt to matrix-supported, clay-rich zones with a markedly bimodal grain-size distribution. There is no clear evidence for cataclasis, although a marked grain size reduction in the sand and silt grains is common across boundaries of the silt and sand clusters. Although most sand- and siltsized grains are nearly equant, the small percentage of elonate grains within the clay-rich zones are weakly aligned subparallel to the trace of the zone. There is no microscopically resolvable preferred orientation of clay minerals in the matrix, even in very thin portions of the thin section.

Open fractures crosscut this fabric and lack a strongly preferred orientation. Large euhedral grains of gypsum (identified optically) bridge many of these fractures and include detrital grains and matrix of the sediment. These gypsum grains were at least in some cases growing contemporaneously with the opening of the fractures, both of which probably occurred during desiccation of the cores.

\section{Scaly Mudstone}

Thin sections cut from an impregnated slab at 267 meters in Hole 492 microscopically document the two fabrics shown by the anastomosing fracture surfaces (see macroscopic description). The earlier foliation, $\mathrm{S}_{1}$, is defined microscopically by a preferred orientation of platy minerals, mostly phyllosilicates (Plate 8, Fig. 1). Textural layering crosscut by $\mathrm{S}_{1}$ at a low angle (Plate 8, Fig. 1) probably represents relict bedding. The $S_{1}$ foliation is folded in places (Plate 8, Fig. 2) and is microscopically pervasive throughout the sediment except where it is crosscut by $\mathrm{S}_{2}$, which is defined by discrete planar zones of reoriented phyllosilicates (Plate 8, Fig. $3)$. The later foliation has apparently formed by mechanical bending of platy mineral grains originally aligned parallel to $S_{1}$ and includes very planar fracture surfaces that macroscopically offset $\mathrm{S}_{1}$ (Plate 8, Fig. 3). Both $S_{1}$ and $S_{2}$ are crosscut by later open fractures that probably opened during recovery of the core. The scaly mudstones studied microscopically show no evidence of cementation.

In Core 492B-1, coarse sand is associated with scaly mudstone in varying proportions (Plate 3, Fig. 1). Thin sections show two foliations in the fine-grained scaly mudstone, both defined by aligned phyllosilicates. The later foliation, $S_{2}$, is less penetrative and crosscuts the more ubiquitous $\mathrm{S}_{1}$ foliation in discrete zones. Apophyses, or stringers, of sand grains extend from sand clusters into the mudstone, trailing out in delicate wisps subparallel to $S_{1}$ (Plate 9, Fig. 1). Coarse sand-sized quartz grains in this sample have clearly been broken (Plate 9, Fig. 2), suggesting deformation under confining pressure (Friedman et al., 1980). The grain breakage could conceivably be due to compaction, although it has not been noted in sediment at similar depths in other holes.

\section{CONCLUSIONS}

The landward increase in age of the zone of landward-tilted reflectors underlying the lower slope and the inferred nature of these reflectors suggest that landward-dipping thrust faults have produced a regional stratigraphic inversion across the lower slope (Moore et al., 1979). However, bedding dips in trench deposits inferred to be uplifted are as steep or steeper in the lowermost slope site as they are farther up on the slope, indicating that tilting of accreted trench sediments is accomplished very near the trench and does not increase significantly upslope.

Contrasting lithologies in the Leg 66 holes provide good resolution of many primary and secondary structures throughout cores recovered at six inner slope sites. Our compilation of bedding tilts, macroscopic and microscopic features of penetrative fabrics, and discrete structures correlates tectonic environments with basement types (Table 1) landward of the Middle America Trench and constrains the conditions under which deformation has initiated at shallow levels.

\section{Tectonic Environments}

The lower slope is the most active environment, tectonically. Cores from lower slope sites exhibit zones of inconsistent bedding dip, stratal disruption, and scaly mudstone. The basement of the lower slope is seismic- 
Table 1. Summary of characteristics of tectonic environments of the Middle America Trench slope defined by structural features of Leg 66 cores.

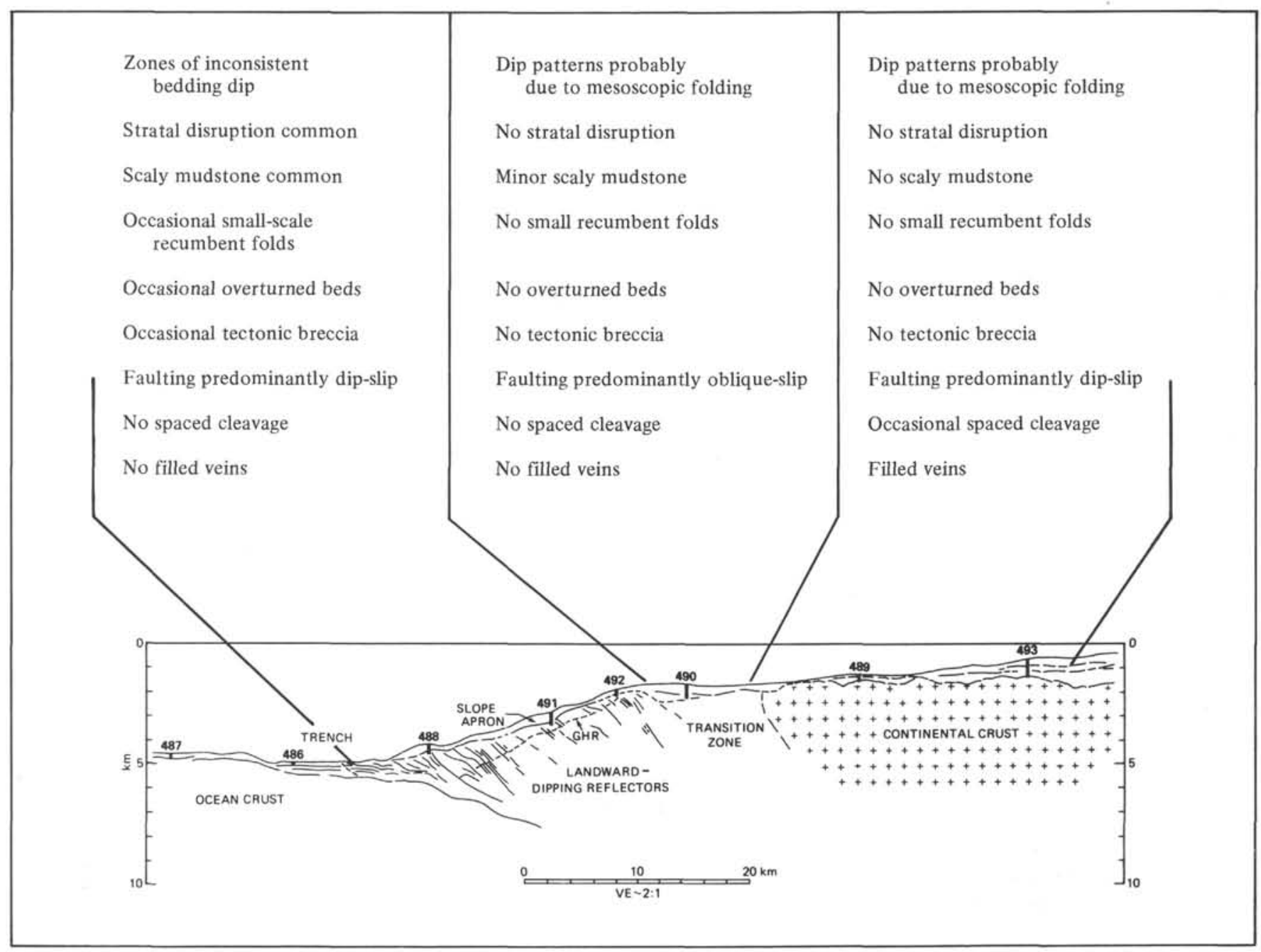

ally defined as a zone of landward-dipping reflectors composed principally of uplifted and tilted trench deposits. It overlies but is generally detached from the actively underthrusting Cocos Plate and includes offscraped hemipelagic and pelagic deposits at depth as well as hemipelagic sediment incorporated from the overlying inner slope blanket. The trench slope seaward of Site 492 records uplift rates ranging from 135 to 800 $\mathrm{m} / \mathrm{m}$.y., with the most rapid rate probably localized at the toe of the slope (McMillen and Bachman, this volume).

Within the lower slope, deformation is more active closest to the trench. The onset of significant tilting of bedding and the first occurrences of scaly mudstone and stratal disruption are restricted to progressively older rocks upslope from Sites 488 to 491 to 492 . Although sediments from shallower environments were recovered at Sites 491 and 492 , cores from all three lower slope sites contain scaly mudstone and stratal disruption only in sediments deposited deeper than $4 \mathrm{~km}$ of water (see site chapters), suggesting that these structural features develop preferentially beneath the lowermost trench slope. This focus of deformational activity beneath the lowermost trench slope is spatially correlative to the most rapid change in tilt of the underlying dipping reflectors (Shipley, this volume) and the most rapid uplift rate (McMillen and Bachman, this volume). Thus if the observed structures are due to gravitational processes, they are accentuated at the toe of the trench slope, probably in response to intensified tectonic activity.

Cores from sites overlying continental crust (Sites 489 and 493) show bedding dip patterns best explained by mesoscopic folding. A spaced foliation and sparsely distributed zeolite(?)-filled veins occur in separate restricted intervals. Sediments recovered at both Sites 489 and 493 reflect rapid subsidence followed by slow uplift, which was preceded by at least one major period of uplift and erosion to expose the schist and diorite.

The transition zone has features common to both the region underlain by dipping reflectors and that underlain by continental crust (Table 1). The basement of the transition zone is unknown, and the sediments recovered in this region (Site 490) record slow uplift. Minor scaly mudstone occurs, but stratal disruption is not evident. No zones of inconsistent dip are present, and the pattern of bedding dips is attributable to mesoscopic 
folding. Spaced foliation, stepped foliation, and filled veins are absent. The transition zone is unique in that discrete fractures with slickensides are dominated by oblique-slip faults, whereas all other sites exhibit mainly dip-slip faults. The predominance of oblique slip may represent a tendency for decoupling between the contrasting basement types in response to any oblique plate convergence in the past five million years.

\section{Implications for Development of Accretionary Complexes}

Stratal disruption and scaly mudstone are characteristics of some melanges, especially argillite-rich terranes, which have been interpreted as uplifted subduction complexes and/or olistostromes (Abatte et al., 1970; Elter and Trevishan, 1973; Hsü, 1974), and occur in cores from Sites 488,491 , and 492 , which penetrate the zone of landward-dipping reflectors. Scaly mudstone is poorly developed in cores from Site 490 in the transition zone. Neither scaly mudstone nor zones of stratal disruption occur in cores from Sites 489 or 493 , which overlie continental basement. Clearly, these deformational features are concentrated beneath the lower slope in trench sediments, probably offscraped, and in the associated lower slope deposits.

Stratal disruption and scaly mudstone are developed both separately and together in Leg 66 cores. Stratal disruption may occur but be unrecognized in scaly mudstone intervals that lack contrasting lithologies. It indicates a mixing event in the formation of this in situ accretionary complex, and the resulting mixture is sedimentologically chaotic, though it contains structurally ordered features. Scaly mudstone represents a penetrative fabric characteristic of many melanges, and in the examples studied it is characterized by the superposition of two secondary surfaces defined by preferred mineral orientations.

The zones of stratal disruption and scaly mudstone penetrated in Leg 66 drilling show physical properties that are probably similar to those that prevail during deformation. The documentation of stratal disruption in partially consolidated mud and unconsolidated sand recovered at Sites 488,491 , and 492 indicates that bedding was disrupted very early in the structural history of these sediments. Dewatering and lithification are far from complete, and it is possible that fracture surfaces in the scaly mudstone serve as dewatering conduits (see also Arthur et al., 1980). This prelithification deformation indicates that strain measurements based on deep diagenetic and low-grade metamorphic phenomena (e.g., quartz fibers) may assess only partially the strain history of uplifted accretionary complexes.

Stratal disruption and scaly mudstone occur both in sediments inferred to represent uplifted and accreted trench deposits and in those of the overlying hemipelagic slope apron. We interpret both phenomena as products of the initial incorporation of partially lithified slope sediments into an evolving accretionary complex.

\section{ACKNOWLEDGMENTS}

Acknowledgment is made to the Donors of the Petroleum Research Fund (PRF 9219-AC2), administered by the American Chemical Society, for the partial support of this research. We thank T. Byrne and our fellow shipboard scientists for stimulating discussions, W. Mills and L. Garifal for assistance during data collection in La Jolla, and Gene Gonzales for skillful preparation of thin sections from partially consolidated muds. E. C. Beutner (Franklin and Marshall College), D. S. Cowan (University of Washington), and M. A. Arthur (U.S. Geological Survey) provided perceptive and helpful reviews. Wayne Zeck of UCLA kindly conducted X-ray fabric studies of spaced foliation samples.

\section{REFERENCES}

Abbate, E., Bortolotti, V., and Passerini, P., 1970. Olistostromes and olistoliths. Sediment. Geol., 4:521-557.

Arthur, M. A., Carson, B., and von Huene, R., 1980. Initial tectonic deformation of hemipelagic sediment at the leading edge of the Japan convergent margin. In Scientific Party, Init. Repts. DSDP, 56, 57, Pt. 1: Washington (U.S. Govt. Printing Office), 569-614.

Cantagrel, J. M., and Robin, C., 1979. K-Ar dating on eastern Mexican volcanic rocks-relations between the andesitic and alkaline provinces. J. Volcanol. Geotherm. Res., 5:99-114.

Cowan, D. S., 1978. Origin of blueschist-bearing chaotic rocks in the Franciscan Complex, San Simeon, California. Geol. Soc. Am. Bull., 89:1419-1423.

Draper, G., 1978. Coaxial pure shear in Jamaican blueshists and deformation associated with subduction. Nature, 275:735-736.

Durney, D. W., and Ramsey, J. G., 1973. Incremental strains measured by syntectonic crystal growths. In De Jong, K. A., and Scholten, R. (Eds.), Gravity and Tectonics: New York (John Wiley and Sons), pp. 67-96.

Elliott, D., 1976. The motion of thrust sheets. J. Geophys. Res., 81B: 949-963.

Elter, P., and Trevishan, L., 1973. Olistostromes in the tectonic evolution of the Northern Apennines. In De Jong, K. A., and Scholten, R. (Eds.), Gravity and Tectonics: New York (John Wiley and Sons), pp. 175-188.

Friedman, M., Hugman, R. H. H., III, and Handin, J., 1980. Experimental folding of rocks under confining pressure Part VIIIforced folding of unconsolidated sand and lubricated layers of limestone and sandstone. Geol. Soc. Am. Bull., 91:307-312.

Hobbs, B. E., Means, W. D., and Williams, P. F., 1976. An Outline of Structural Geology: New York (John Wiley and Sons).

Hsü, K. J., 1974. Melanges and their distinction from olistostromes. In Dott, R. H., Jr., and Shaver, R. H. (Eds.), Modern and Ancient Geosynclinal Sedimentation: Tulsa (Society of Economic Paleontologists and Mineralogists), Special Publication 19, 321333.

Karig, D. E., Cardwell, R. K., Moore, G. F., et al., 1978. Late Cenozoic subduction and continental margin truncation along the northern Middle America Trench. Geol. Soc. Am. Bull., 89:265276.

Maxwell, J. C., 1974. Anatomy of an orogen. Geol. Soc. Am. Bull., 85:1195-1204.

Mejorada, S. H. S., 1976. Carta Geológica de la Republica Mexicana (4th ed.): Mexico City (Instituto de Geología, U.N.A.M. Ciudad Universitaria).

Minster, J. B., and Jordan, T. H., 1978. Present-day plate motions. J. Geophys. Res., 83B:5331-5354.

Moore, J. C., and Karig, D. E., 1976. Sedimentology, structural geology and tectonics of the Shikoku subduction zone. Geol. Soc. Am. Bull., 87:1259-1268.

Moore, J. C., Watkins, J. S., Shipley, T. H., et al., 1979. Progressive accretion in the Middle America Trench, southern Mexico. $\mathrm{Na}$ ture, 281:638-642.

Quinquis, H., Audren, Cl., Brun, J. P., et al., 1978. Intense progressive shear in Île de Groix blueschists and compatibility with subduction or obduction. Nature, 273:43-45. 
Scholl, D. W., von Huene, R., Vallier, T. L., et al., in press. Sedimentary masses and concepts about tectonic processes at underthrust ocean margins. Geology.

Seely, D. R., 1977. The significance of landward vergence and oblique structural trends on trench inner slopes. In Talwani, M., and Pit- man, W. C., III (Eds.), Island Arcs, Deep Sea Trenches and BackArc Basins: Maurice Ewing Series I: Washington (American Geophysical Union), pp. 187-198.

Silver, E. A., and Beutner, E. C., 1980. Melanges. Geology, 8:32-34. 

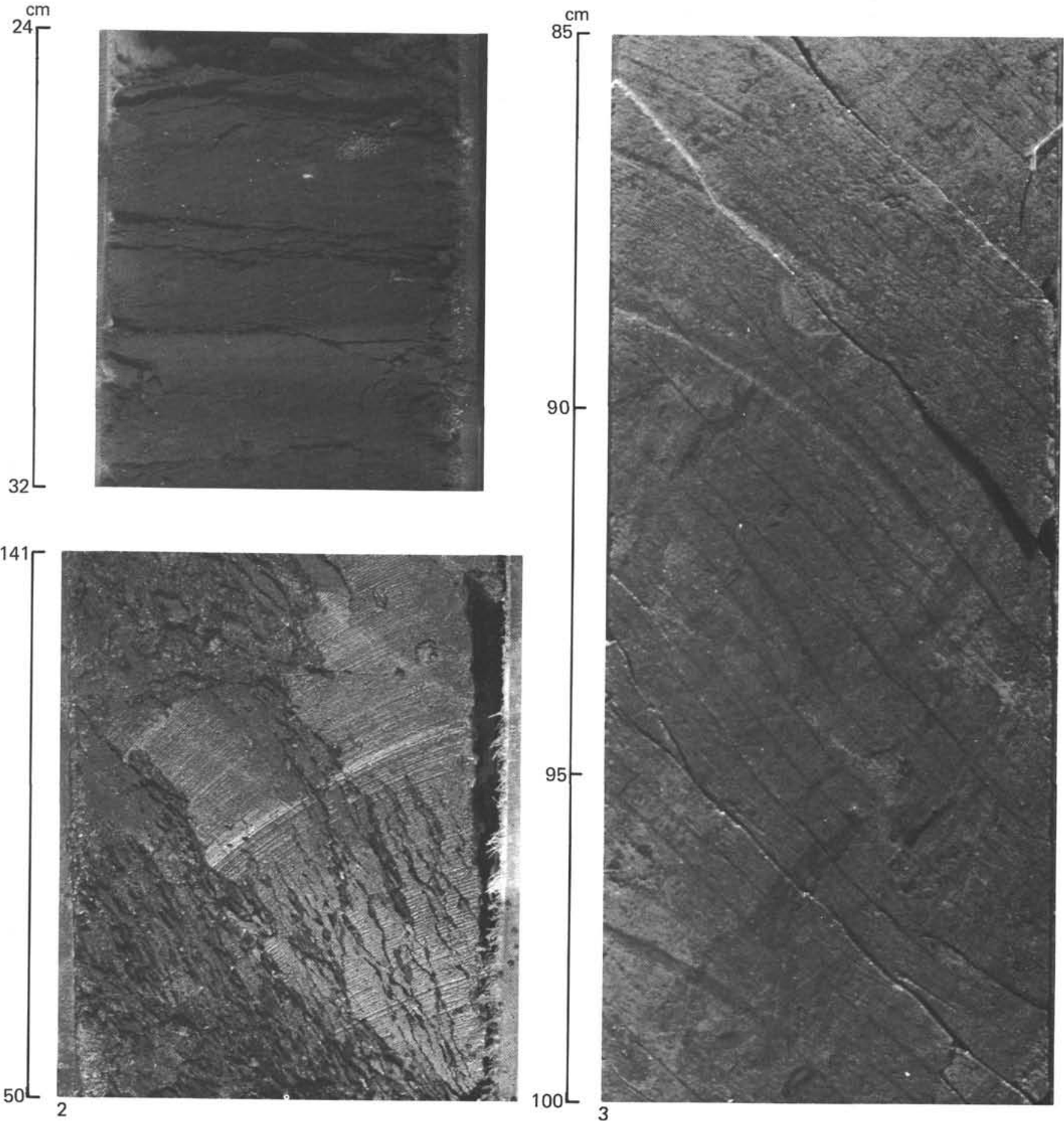

2

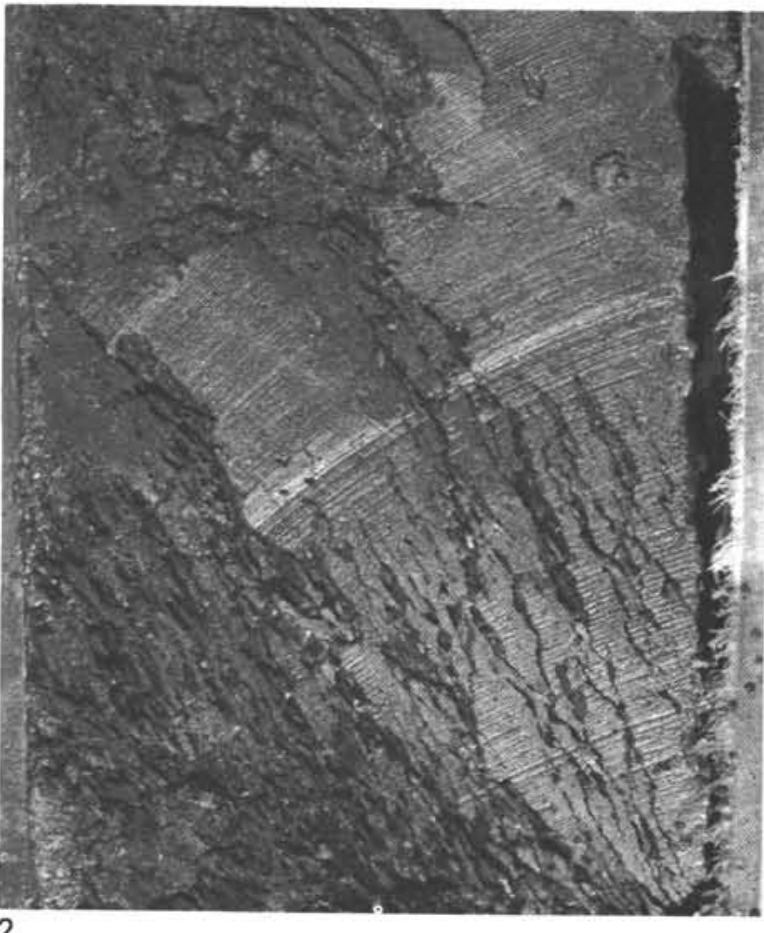

3

Plate 1. Foliations in Leg 66 cores. 1. Fissility, defined by shaly parting surfaces parallel to bedding, developed in laminated mudstone. Interval 493-21-2, 24-32 cm $(302 \mathrm{~m})$. 2. Stepped foliation, defined by shaly parting surfaces that crosscut bedding at a steeper angle, in mudstone. Interval 493-18-2, 141-150 cm $(275 \mathrm{~m})$. Curved striations are saw marks. 3. Spaced foliation, defined by parallel dark zones of fine-grained material that crosscut bedding at nearly $90^{\circ}$, in bioturbated mudstone. Interval $489 \mathrm{~A}-11-4,85-100 \mathrm{~cm}(127.5 \mathrm{~m})$. 

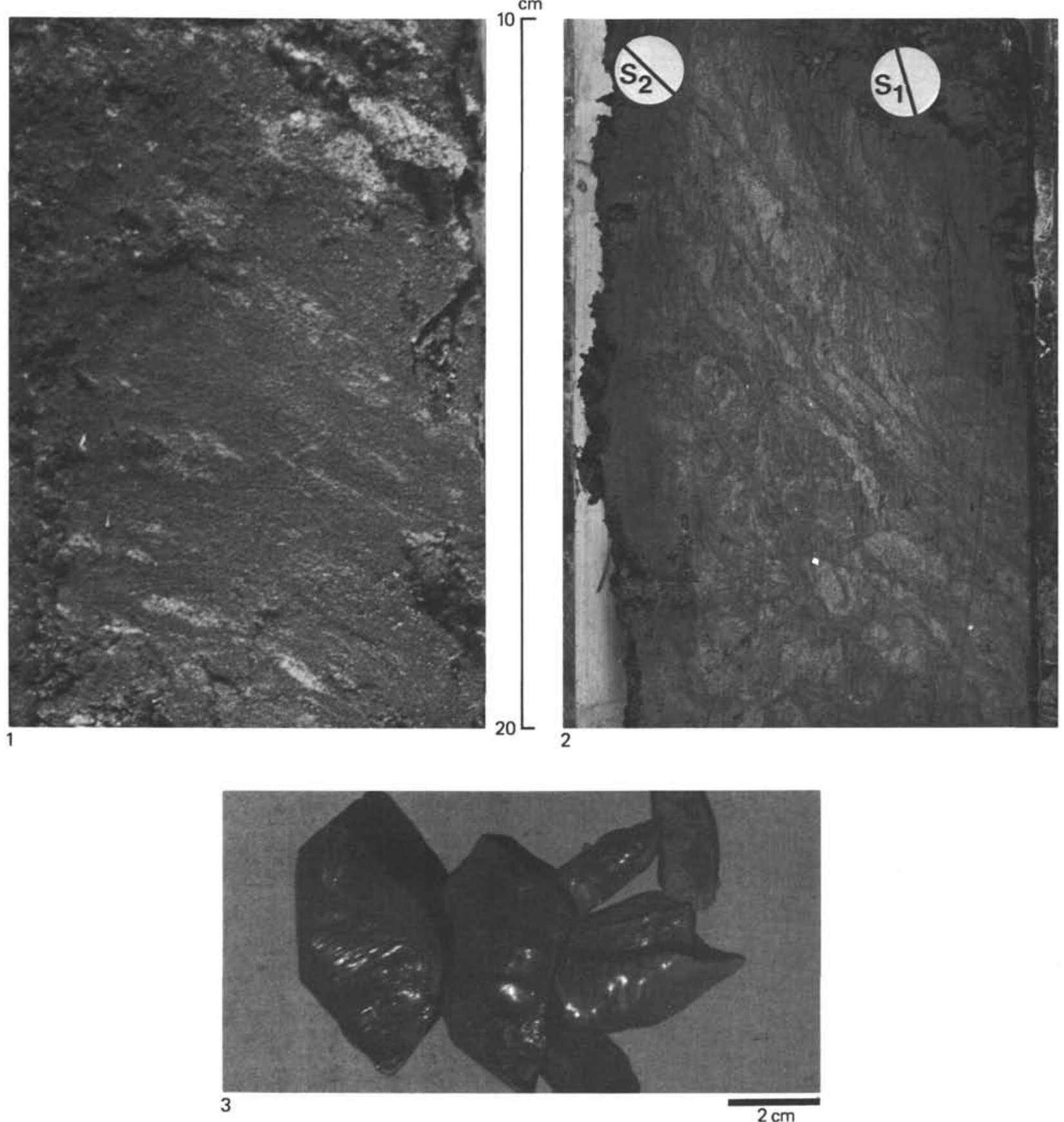

Plate 2. Examples of stratal disruption and scaly mudstone. 1. Stratal disruption in mud, silt, and sand. Interval $488-26-6,133-143 \mathrm{~cm}(238 \mathrm{~m})$. A planar foliation is defined by elongate lenses of silt to fine sand and, locally, by thin, dark zones of fine-grained material. 2. Stratal disruption in scaly mudstone, silt, and fine sand. Interval $492-30-2,10-20 \mathrm{~cm}(267 \mathrm{~m})$. A foliation $\left(\mathrm{S}_{1}\right)$ defined by elongate lenses of silt to fine sand and by thin, dark zones of fine-grained material is crosscut by a shallower-dipping later foliation $\left(\mathrm{S}_{2}\right)$ defined by a fainter set of similar thin, dark zones. Bedding is not resolvable. 3. Scaly mudstone chips, exhibiting a pervasive fabric of anastomosing polished and slickensided fracture surfaces. Interval 490-60-1, 34-48 cm (541 m). 

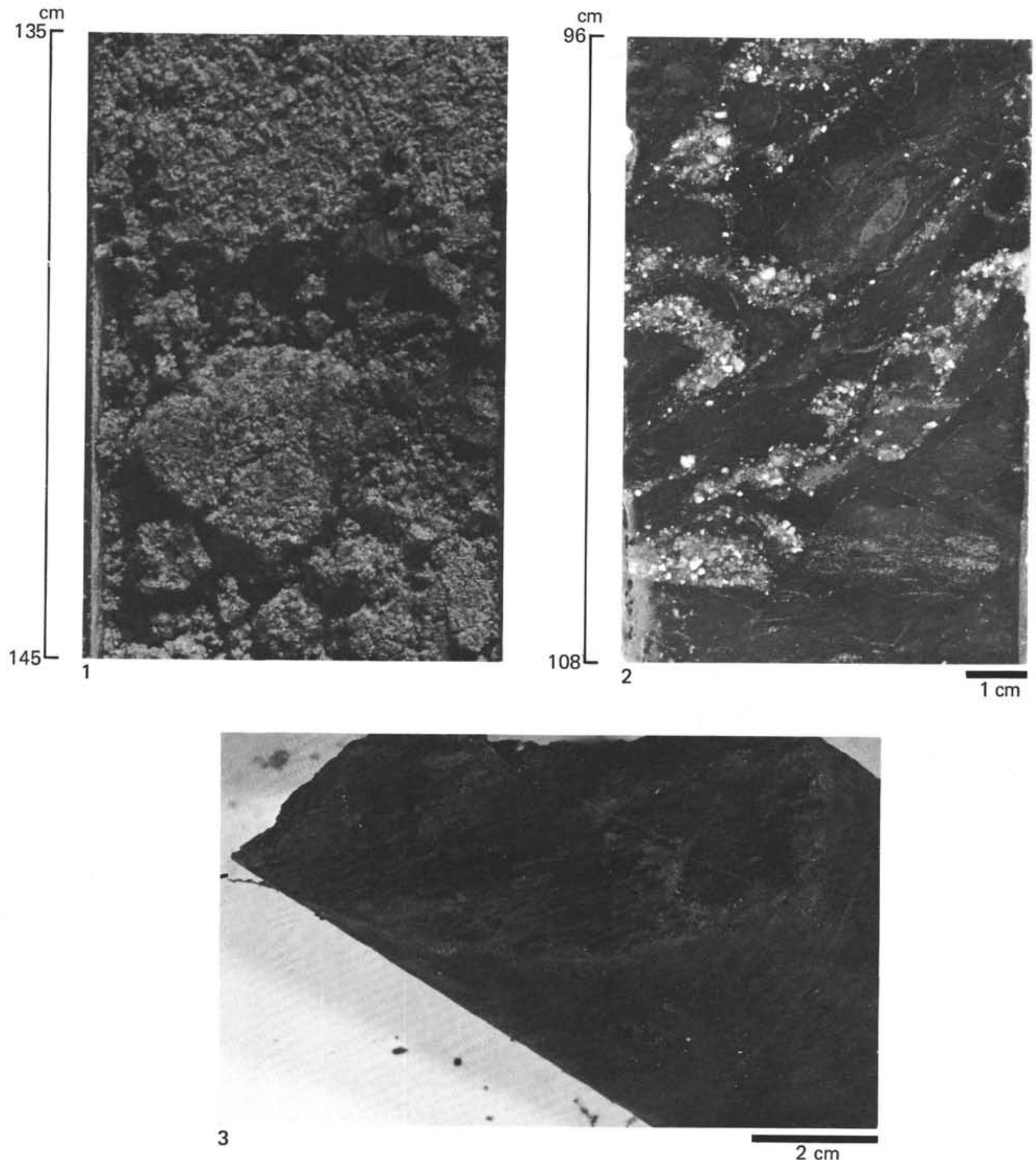

Plate 3. Example of scaly mudstone and discrete fracturing. 1. Chips of scaly mudstone in coarse sand. Interval $492 \mathrm{~B}-1-1,135-145 \mathrm{~cm}$ (281 m). 2. Complexly intermixed scaly mudstone and sand. Interval 492B-1-5, $96-108 \mathrm{~cm}(287.5 \mathrm{~m})$. A semipenetrative planar fabric is defined by anastomosing healed fracture surfaces. Bedding is preserved locally. 3. Slickensided and striated discrete fracture surface in mudstone. Interval $490-55-1,130-140 \mathrm{~cm}(495 \mathrm{~m})$. 
20

$\coprod^{c m}$

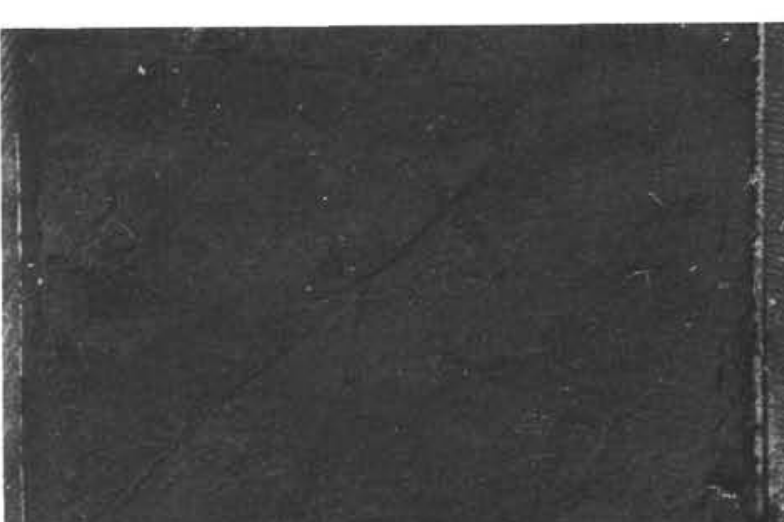

$70 \stackrel{\mathrm{cm}}{\mathrm{C}}$

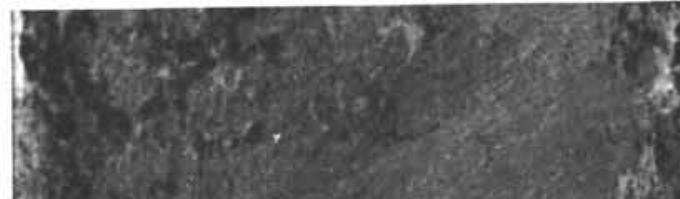

is

$(9$

.

(3)

\&

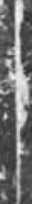

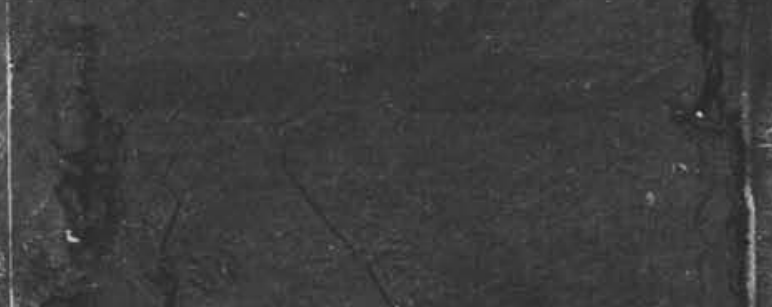

1.
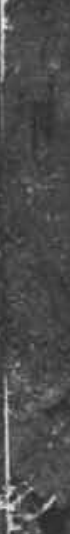

(c)

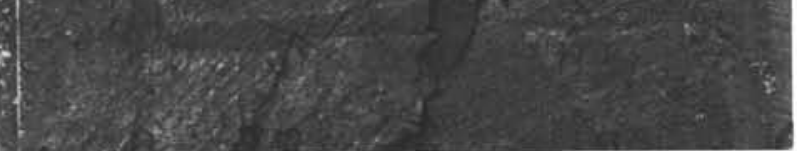
1
87 L

2

Plate 4. Examples of artificial fracturing and a small recumbent fold. 1. Conjugate set of normal faults that offset drilling laminations clearly postdate drilling. Interval 491-26-5, 20-34 cm $(225 \mathrm{~m})$. 2. Small recumbent fold in mudstone. Interval $492-26-4,70-87 \mathrm{~cm}(237 \mathrm{~m})$. 

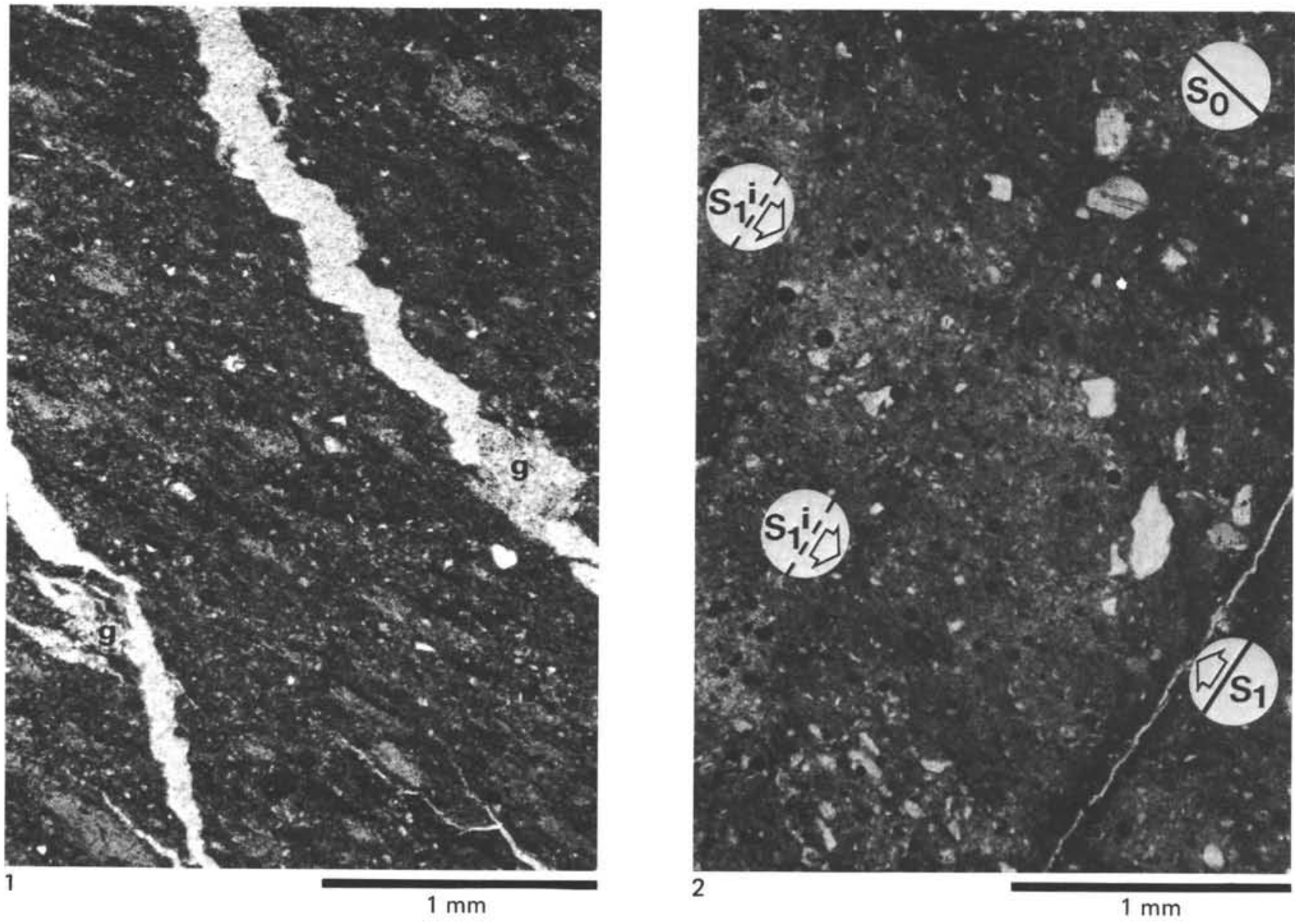

Plate 5. Foliations in Leg 66 cores. 1. Stepped foliation: open fractures crosscutting bedding, 275 meters, Site 493. Sheaves of gypsum (g) are probably due to postdrilling desiccation of the core (plane light). 2. Spaced foliation: parallel zones of dark staining and reoriented platy minerals bound fracture surfaces $\left(\mathrm{S}_{1}\right.$, lower right) and define incipient (prefracture) foliation traces $\left(\mathrm{S}_{1}{ }_{1}{ }^{\text {, }}\right.$, upper left). 127.5 meters, Site 489. Bedding $\left(\mathrm{S}_{0}\right)$ crosses this field of view from upper left to lower right, nearly $90^{\circ}$ to the foliation (plane light). 

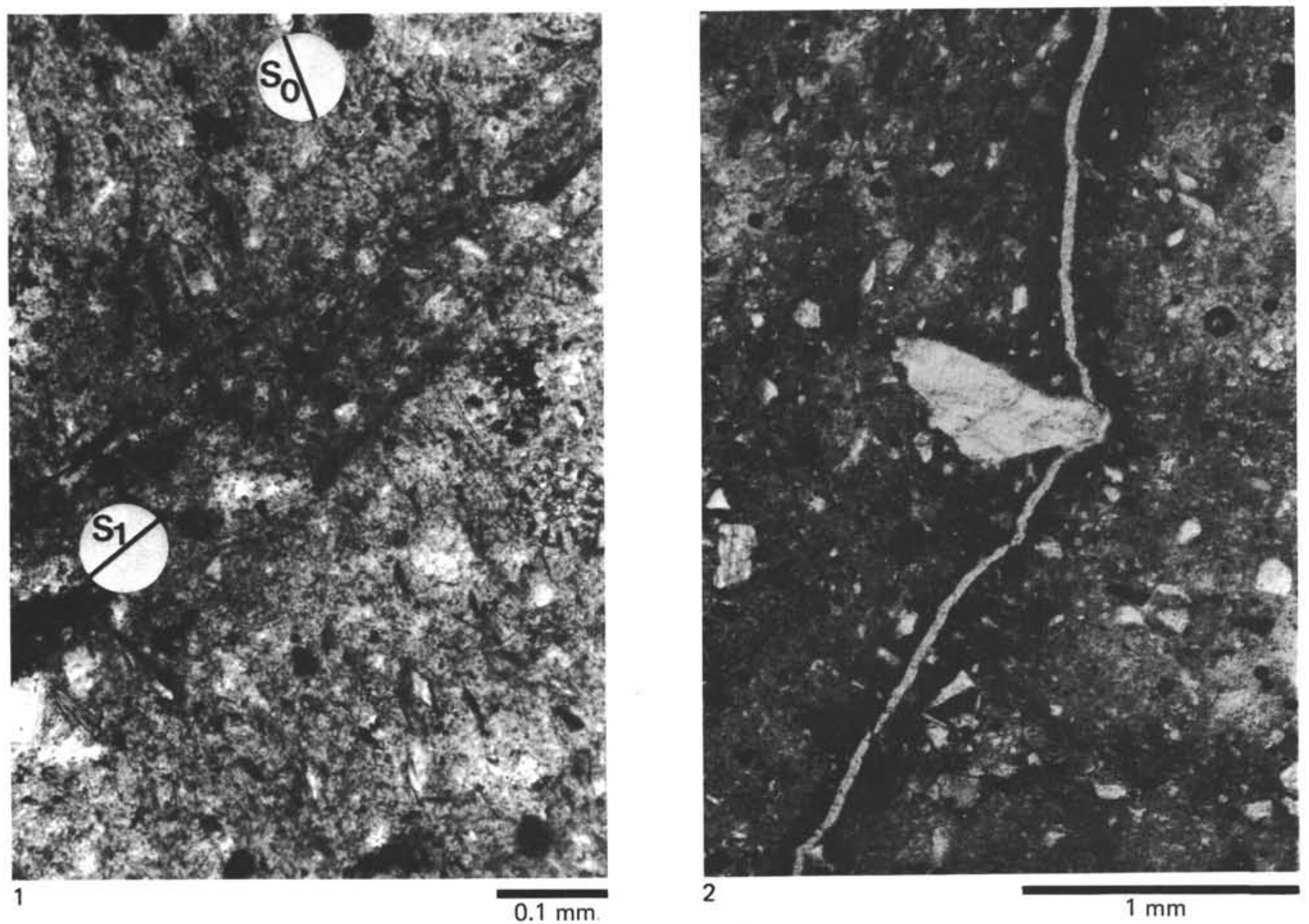

Plate 6. Spaced foliation in Leg 66 cores. 1. Close-up of foliation trace at far left of Plate 5, Fig. 2, showing absence of resolvable kinking of reoriented mineral grains (plane light). 2. Sinuous foliation trace detouring around sand grain. 127.5 meters, Site 489 (plane light). 

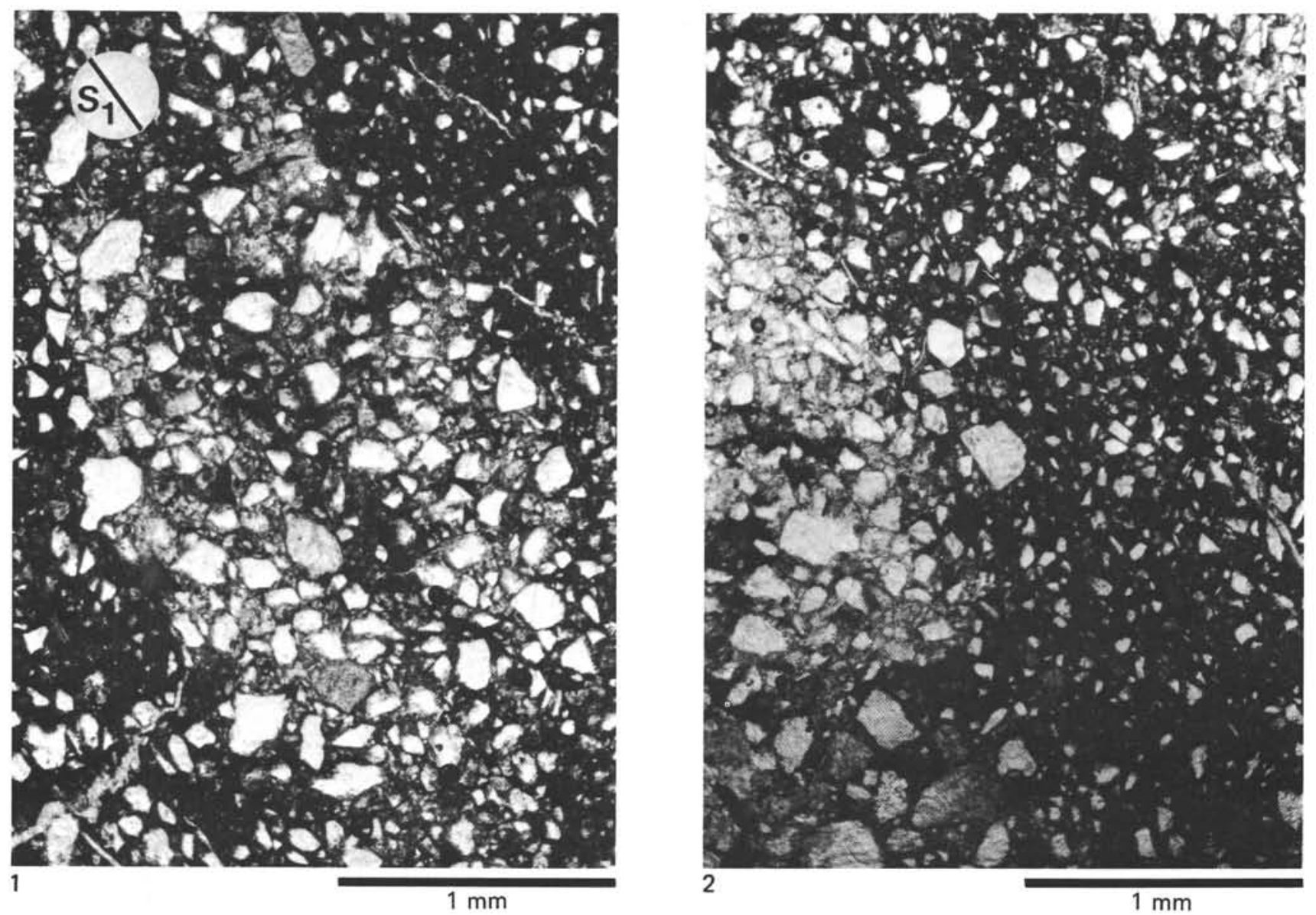

Plate 7. Stratal disruption, 238.5 meters, Site 488 (plane light). 1. Subparallel curviplanar concentrations of clay ( $\left.\mathrm{S}_{1}\right)$ separate clusters of sand and silt. 2. Coherent clusters of sand and silt appear to be disaggregating by the spalling off of individual drains into the bounding clay-rich zones. 


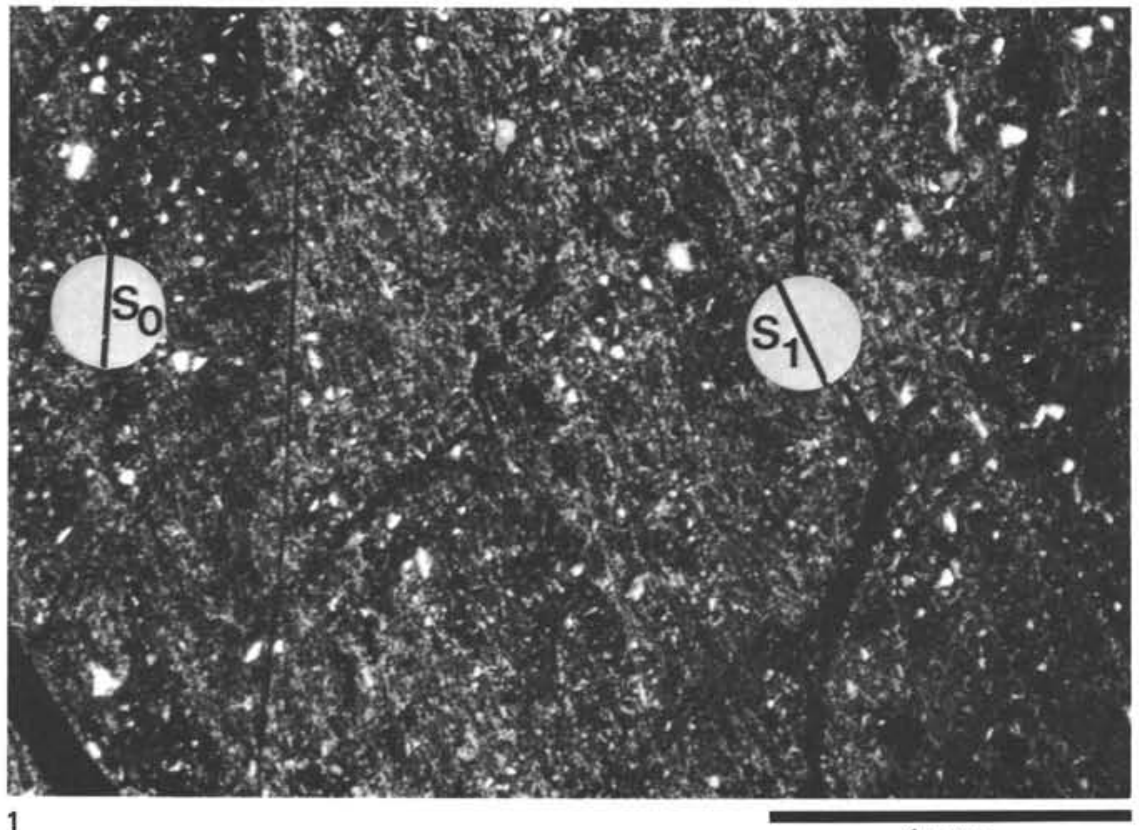

$1 \mathrm{~mm}$

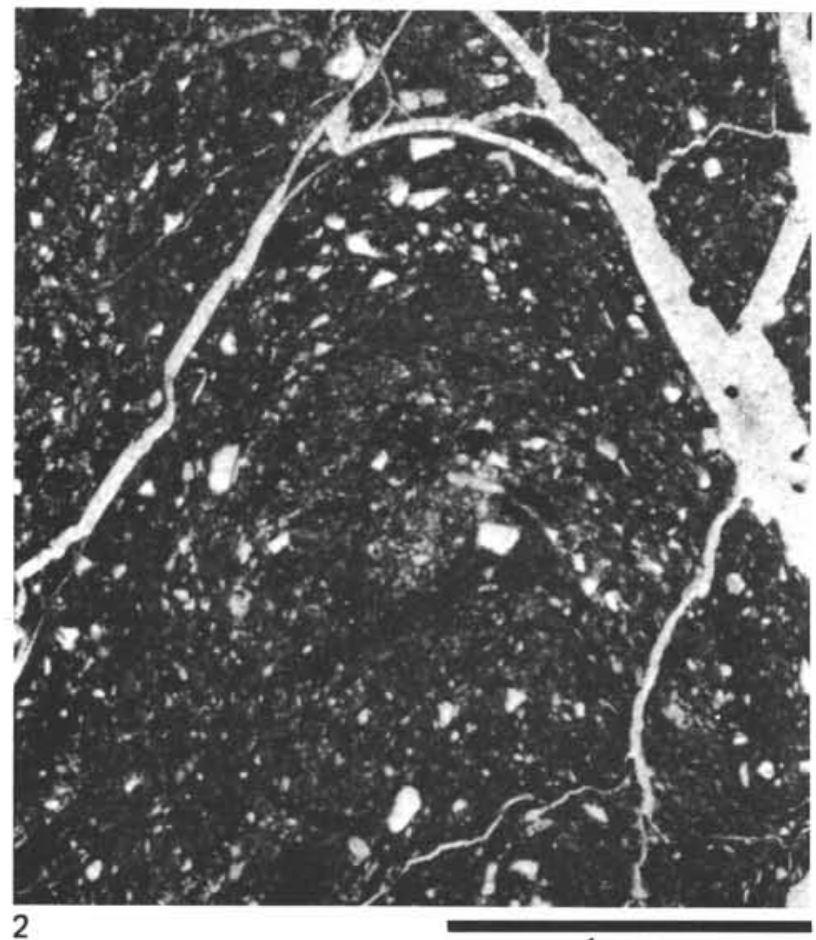

$1 \mathrm{~mm}$

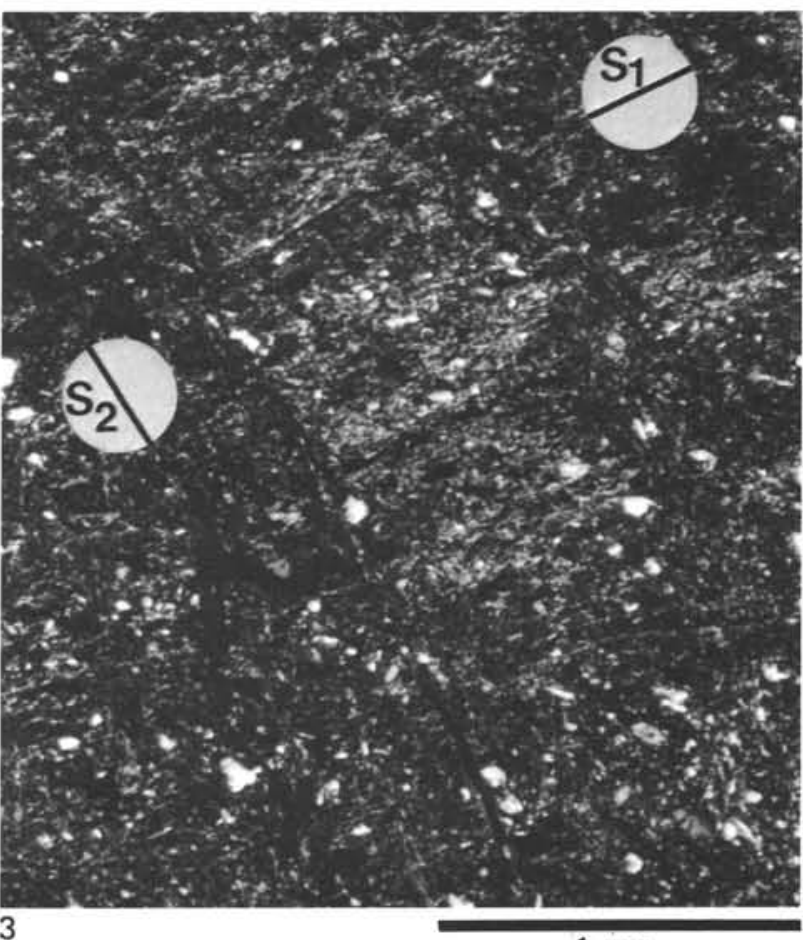

$1 \mathrm{~mm}$

Plate 8. Scaly mudstone, 267 meters, Site 492 . 1. A preferred orientation of phyllosilicates defines a pervasive foliation $\left(\mathrm{S}_{1}\right)$ that crosscuts probable bedding $\left(\mathrm{S}_{0}\right.$, near-vertical coarser-grained zones) at a low angle (crossed nicols). 2. Folded $\mathrm{S}_{1}$ foliation (plane light). 3. $\mathrm{S}_{1}$ (light fabric, inclined gently to the left) crosscut by $\mathrm{S}_{2}$ (dark fabric, inclined steeply to the right). The later foliation has apparently formed by mechanical bending of phyllosilicates originally aligned parallel to $S_{1}$ (crossed nicols). 

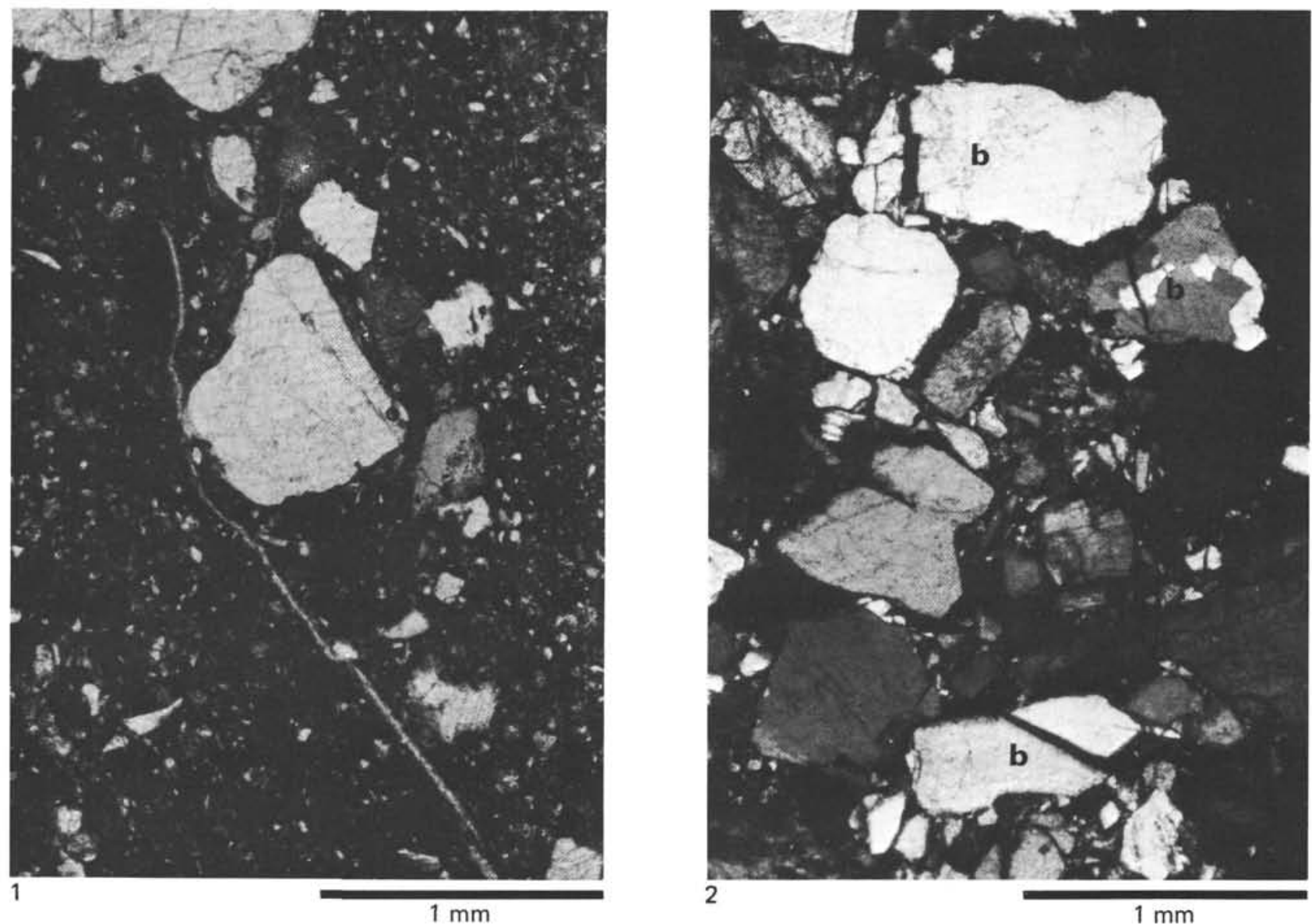

Plate 9. Scaly mudstone, 286 meters, Site 492. 1. Stringers of sand grains extending into mudstone matrix (plane light). 2. Broken sand-sized quartz grains (b) (crossed nicols). 